\title{
Ear Anatomy
}

\section{Ghada M Wageih Felfela*}

Faculty of Medicine, Cairo University, Egypt

Submission: February 04, 2017; Published: February 23, 2017

*Corresponding author: Ghada M Wageih Felfela, Doctor of Audiology Specialist - Health Insurance, M.Sc. of Audio-Vestibular medicine, Faculty of Medicine, Cairo University, Egypt, Tel: 1222349660; Email: ghadawageih@outlook.com

\section{Introduction}

(Figure 1)

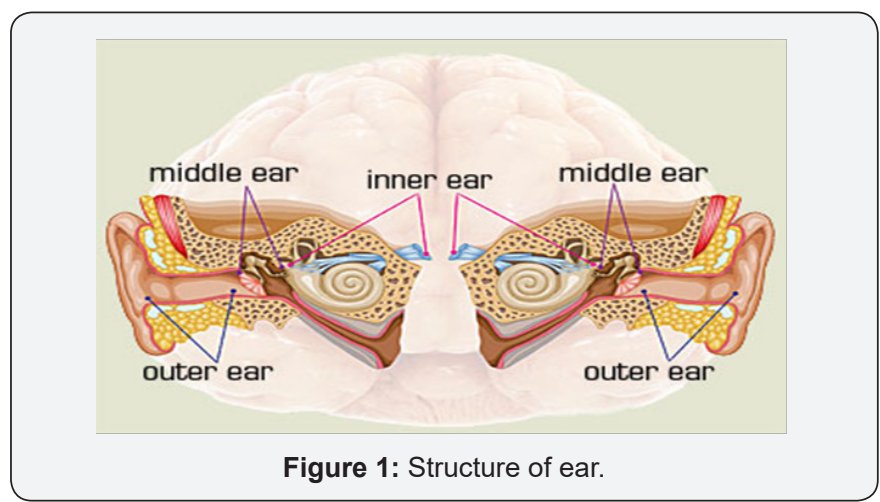

External ear (Figure 2)

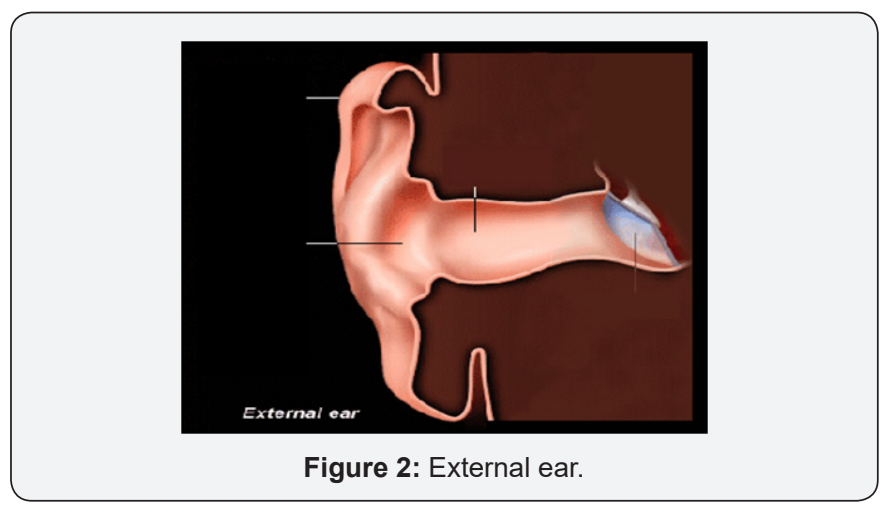
a) Pinna or Auricle
b) External Auditory Canal
c) Tympanic membrane

Pinna : (Figure $3 \& 3.1$ )

Single piece of yellow Elastic cartilage except at: The ear lobule and incisura terminalis: depression between the tragus and the anterior crus of helix. Cartilage is avascular structure - > covered by perichondrium, from which it derives its nutrients. Skin of the pinna is thin and closely attached to the perichondrium on the lateral surface -> more prone to frost bite, while on the medial surface, there is subdermal adipose tissue, that allows for dissection during pinnaplasty and commonest site for sebaceous cyst.
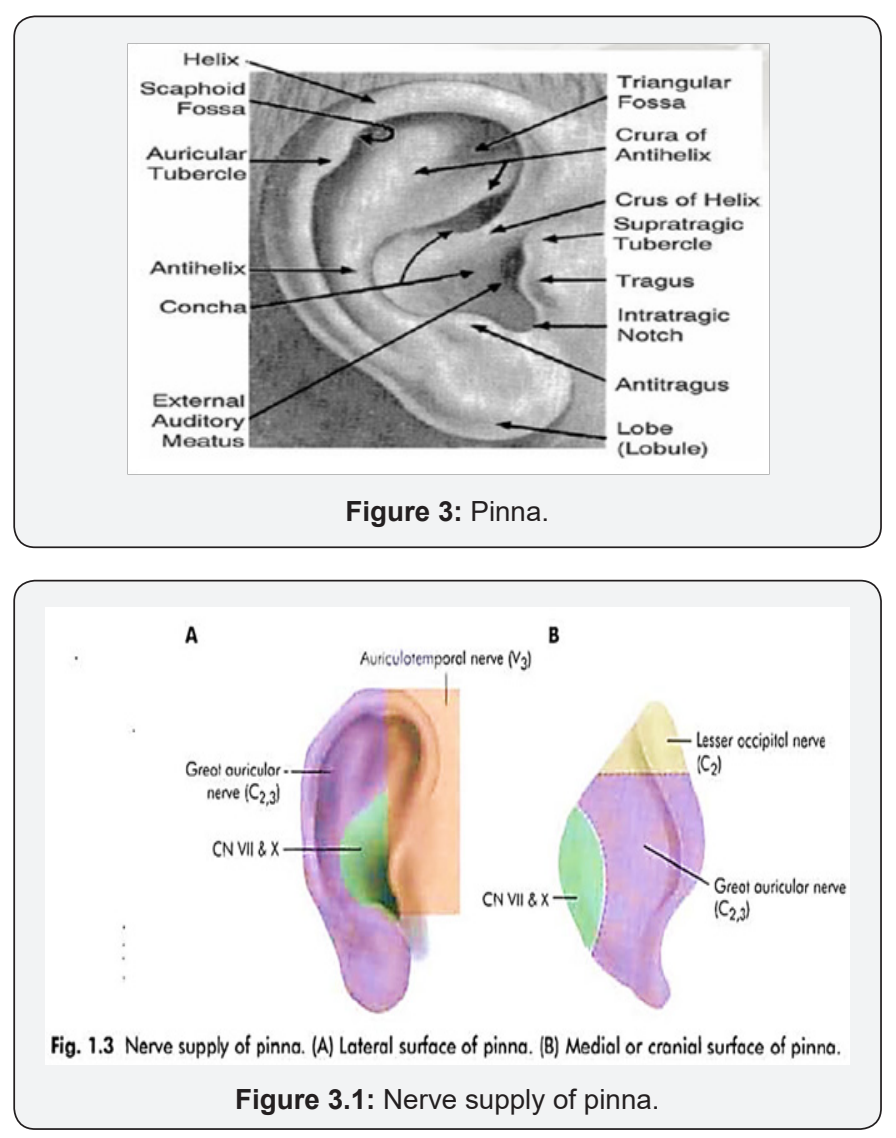

i. Hair: Fine hair at the concha and scaphoid fossa. Thick coarse hair if present -> over the tragus and intertragic notch.

ii. Ligaments: Extrinsic -> anterior (between tragus and helix) and -> posterior (betweeen medial surface of concha and mastoid) Intrinsic ligaments.

iii. Muscles: 3 extrinsic muscles: auricularis anterior, superior and posterior -> from aurile to epicranial 
aponeurosis ->supplied by the Temporal and posterior auricular branches of the facial nerve. 6 Intrinsic ms. -> (without useful function in human)

a. Arterial supply

\section{i. External carotid artery}

ii. posterior auricular artery: supplies the medial surface (except the lobule)

iii. Occipital a: Small auricular br for medial surface

iv. superficial temporal: Anterior auricular a. Superior Auricular a.-> anastomoses with post. Aur.a -> provide a reliable vascular pedicle for retroauricular flaps (Figure 4).

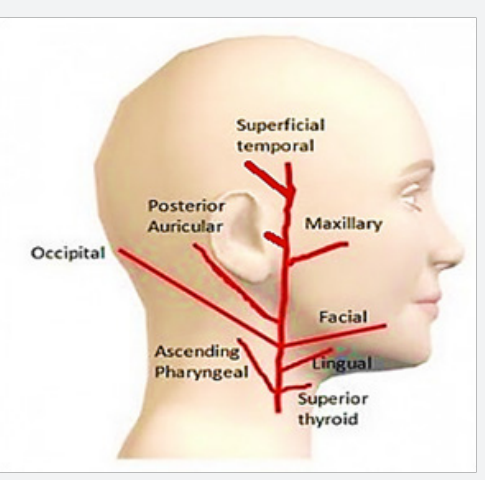

Figure 4: Arterial supply.

Venous drainage -> accompanying arterial supply and drain in External Jugular vein (Figure 5).
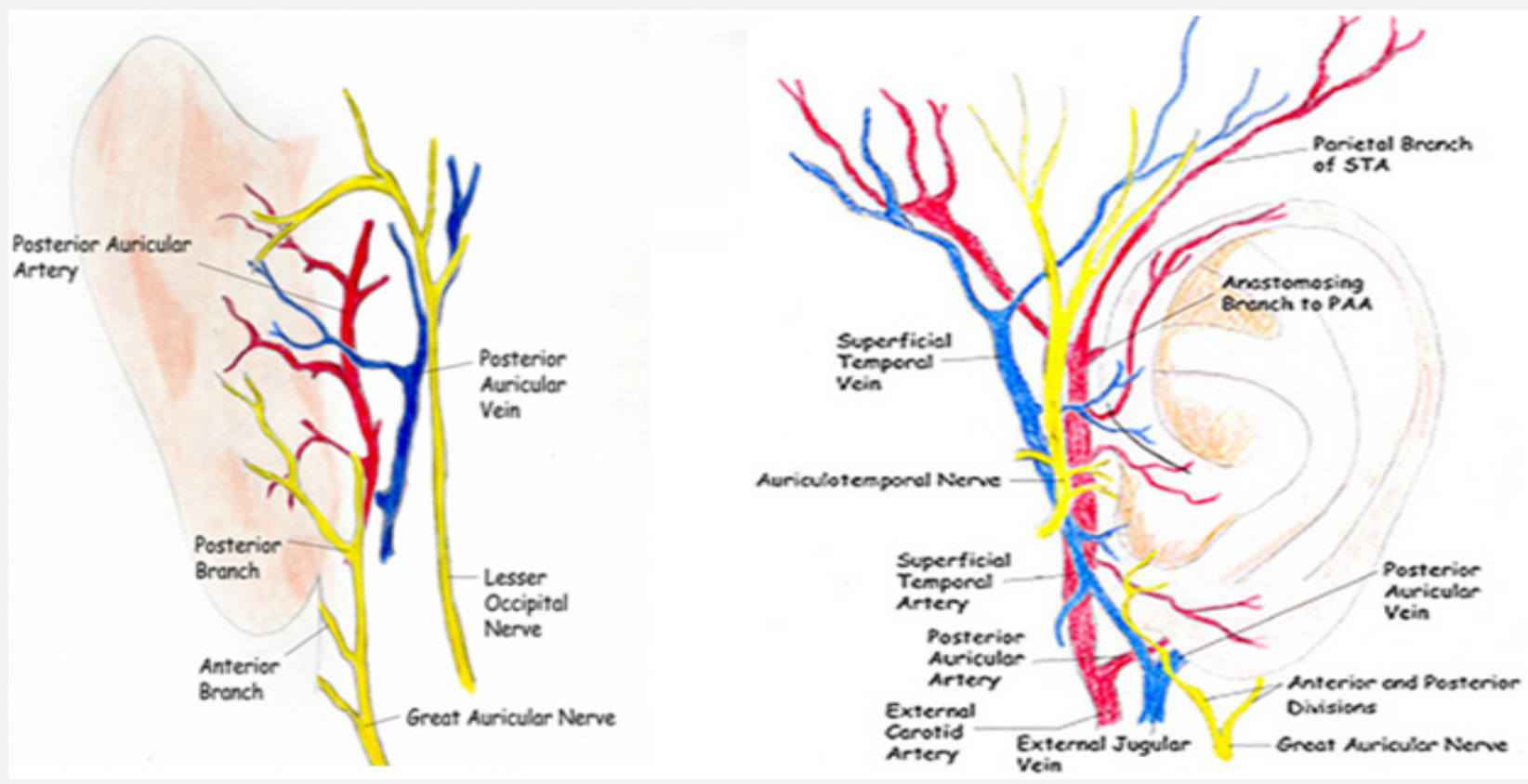

Figure 5: Venous drainage.

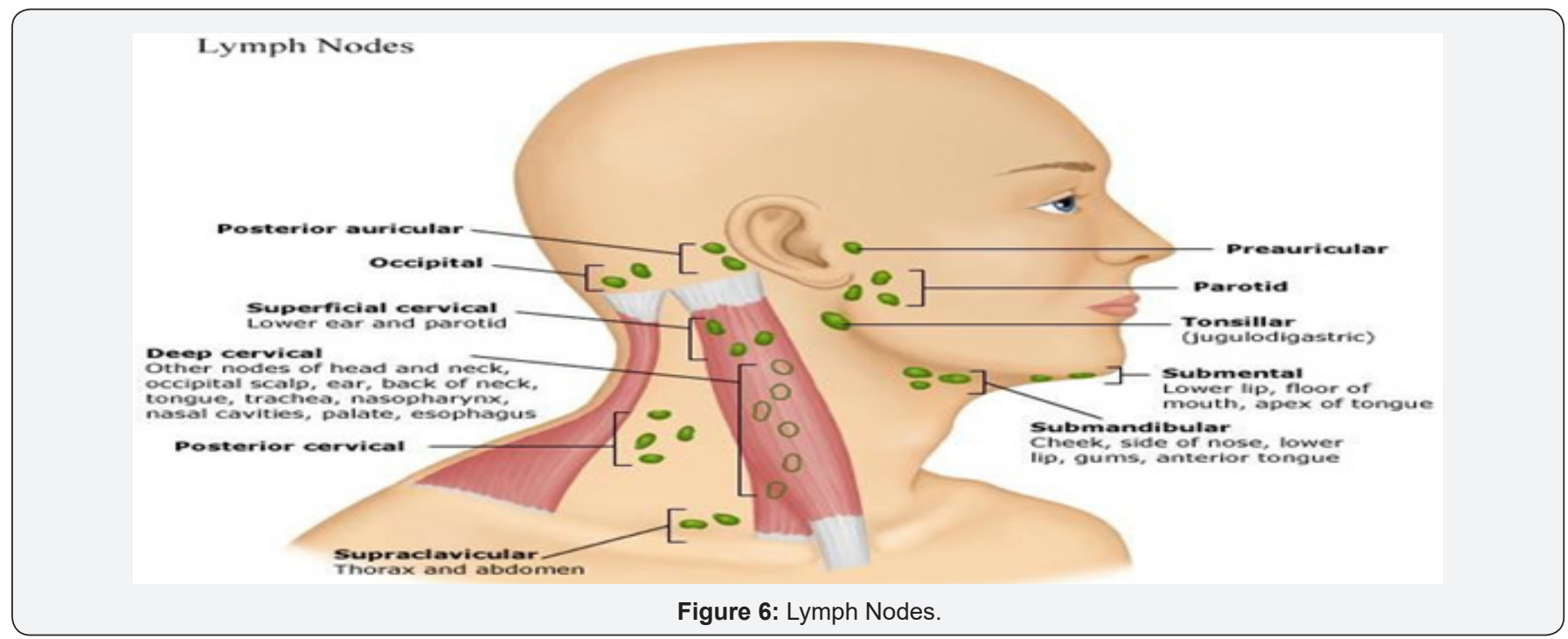




\section{Lymphatic Drainage:}

a) mastoid LN,

b) preauricular

c) parotid LN,

d) Upper deep and

e) superficial cervical LN (Figure 6).

\section{External Auditory Canal}

a. Dimensions: $9 \mathrm{~mm}$ high $\mathrm{X} 6.5 \mathrm{~mm}$ wide, and is roughly $2.5 \mathrm{~cm}$ long. Anterior wall is $6 \mathrm{~mm}$ longer than posterior wall

b. Shape: S-shaped pathway. In the neonate, the tympanic bone is not yet developed, and the tympanic membrane is more horizontally.

c. Parts: The outer third $(8 \mathrm{~mm})->$ cartilage directed upwards and backwards-> continuation of pinna cartilage and the inner two thirds $(17 \mathrm{~mm}) \rightarrow$ Bone, directed downwards and forwards -> formed by squamous part of temporal bone. The skin of cartilaginous portion only contains hairs, sebaceous (oil) and ceruminous (wax) glands. -> lubricating, antimicrobial function, slightly acidic.

\section{d. Anatomical Landmarks:}

a) Two deficiencies: Fissures of Santorini in the cartilage -> the parotid or superficial mastoid infections can appear in the canal, or vice versa - Foramen of Huschke in the the bony canal -> infections to and from the parotid.

b) Two suture lines: Tympanosquamous anteriorly, Tympanomastoid posteriorly, **overlying closely adherent skin, which can makes raising an intact flap a difficult.

c) Two constrictions in the canal: At the junction of the cartilaginous and bony portions. The isthmus, $5 \mathrm{~mm}$ from the tympanic membrane where a prominence of the anterior canal wall reduces the diameter. Anterior Recess: medial to isthmus.

d) Relations of Bony EAC:

i. Superior: middle cranial fossa

ii. Anterior: TM Joint

iii. Medial: Tympanic membrane

iv. Inferior: parotid

v. Posterior: mastoid antrum, air cells. Facial n.

vi. Lateral: cartilaginous portion.

vii. Epithelial migration: self cleansing mechanism, migration from medial to lateral, sloughed with wax (Figure 7).
f) Arterial Supply
g) External Carotid Artery
h) Superficial temporal

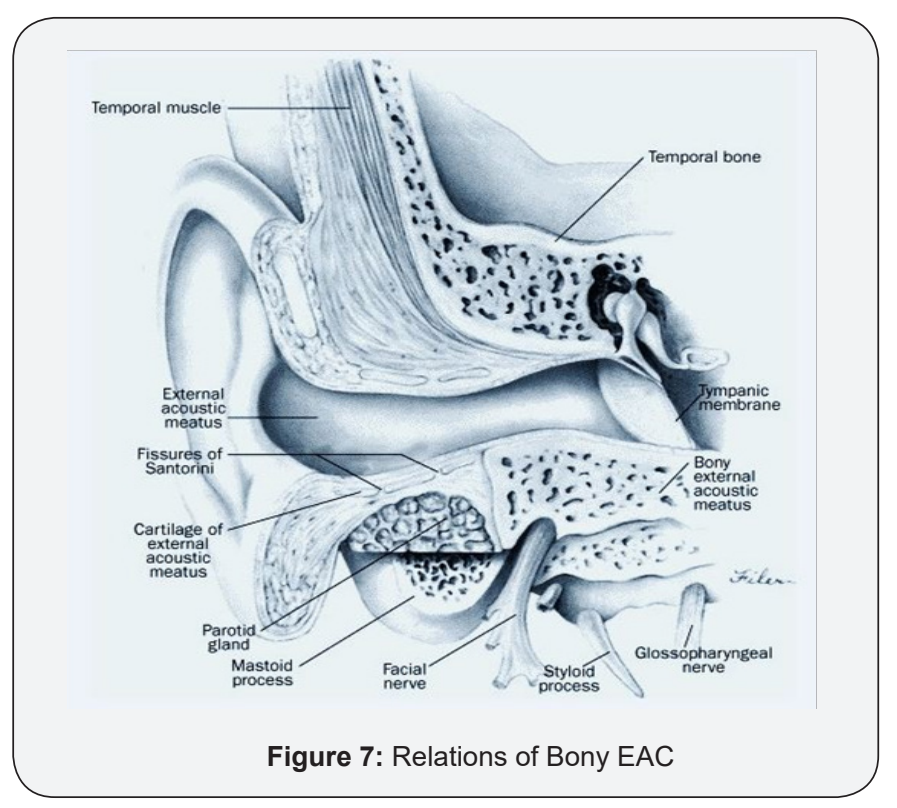

Auricular branches.

Roof and anterior canal portion.

a) Maxillary Artery (1st part): Deep auricular a. The anterior wall and outer surface of the tympanic membrane

\section{posterior auricular artery}

Auricular branches

Posterior portions of the canal.

b) Venousdrainage: - into the External jugular vein, Maxillary veins - Pterygoid plexus.

The lymphatic drainage follows that of the auricle.

i. Sensoryinnervations:

a) Roof and anterior wall -> The auriculotemporal nerve (from the mandibular branch of the trigeminal nerve).

b) Floor and posterior wall -> auricular branch of vagus (Arnold nerve).

Facial n. supply skin of mastoid and posterior EAC -> Hypoesthesia of it occur with facial $\mathrm{n}$ compression in acoustic neuroma, sign called Hitzelberger's sign.

c) Tympanic plexus offers some contributions

\section{Tympanic membrane}

a. Shape and Dimensions: Oval in shape (broader above than below), Thickness $->0.074 \mathrm{~mm}$. Taller $(0.9$ to $1.0 \mathrm{~cm})$ than 
it is wide ( 0.8 to $0.9 \mathrm{~cm}$ ), Concave outward rather than flat. The peak of the cone-like inward displacement is called the umbo.

b. Position: Forming an angle of about $55^{\circ}$ with the floor of the meatus. Tympanic annulus $->$ a circumferential fibrocartilagenous ring sits in tympanic sulcus except at Rivinus notch at canal roof.

c. The eardrum layers: -lateral layer $\rightarrow$ is continuous with the skin of the ear canal, -medial layer -> is continuous with middle ear mucous membrane -between them lamina propria -> 2 layers -> radial fibers, and concentric circular fibers. In the pars flaccida, the lamina propria is less marked and the orientation of the collagen fibres seems random.

\section{d. Anatomical Landmarks:}

Tympanic membrane (left).

1. Malleus

2. anterior mallear fold

3. posterior mallear fold

4. pars flaccida (Shrapnel's membrane)

5. projection of the long process of the incus

6. pars tensa

7. annular ligament (Figure 8).
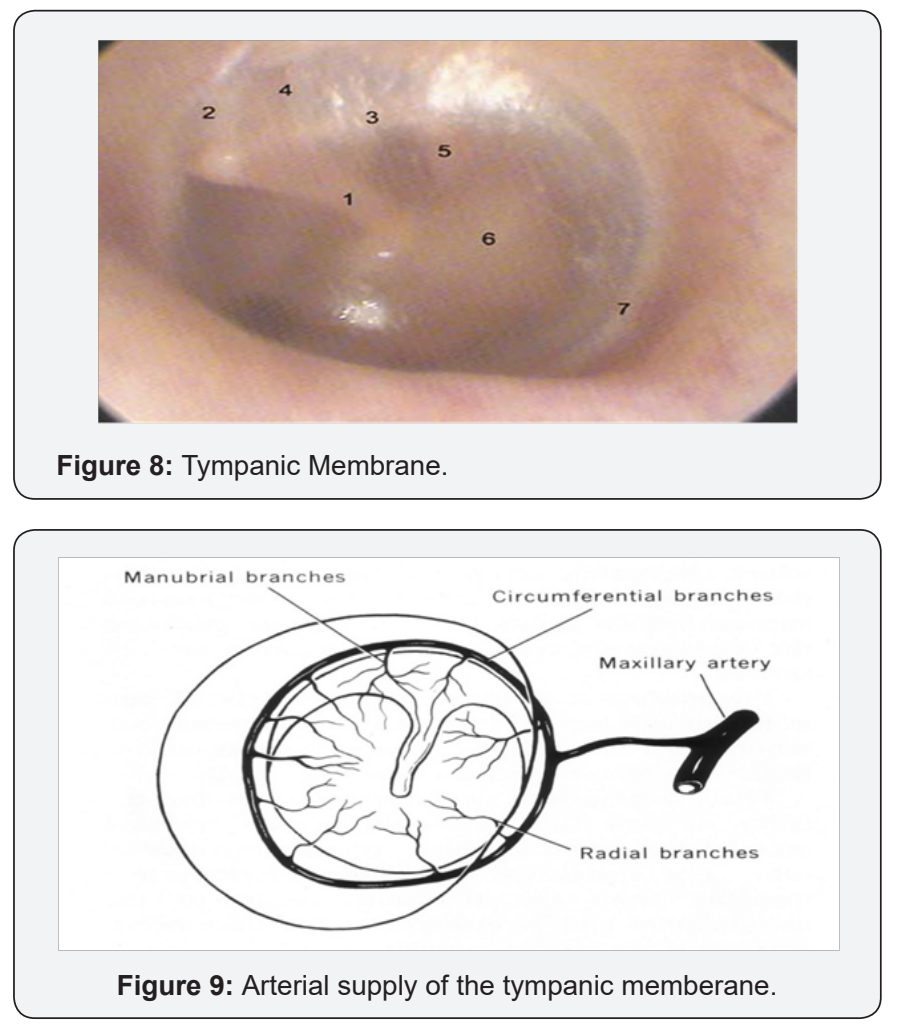

1) Arterial supply of the tympanic membrane: arises from branches supplying both the external auditory meatus and the middle ear $->$ extensive anastomoses within the lamina propria. From the external auditory meatus ->
Deep auricular branch of the maxillary artery. rom middle ear -> Anterior tympanic branches of the maxillary artery, stylomastoid branch of the posterior auricular artery, middle meningeal artery (Figure 9).

\section{2) Nerve Supply:}

I. Lateral surface: Auriculotemporal $\mathrm{N}$ and Auricular $\mathrm{Br}$ of Vagus

\section{(Arnold n).}

II. Medial surface: Tympanic Branch of glossopharyngeal N (Jacobson n.). Minor contributions from CN VII (7)

NB: Both the vascular supply and innervations decrease relatively in the middle part of the posterior half of the tympanic membrane (Figure 10).

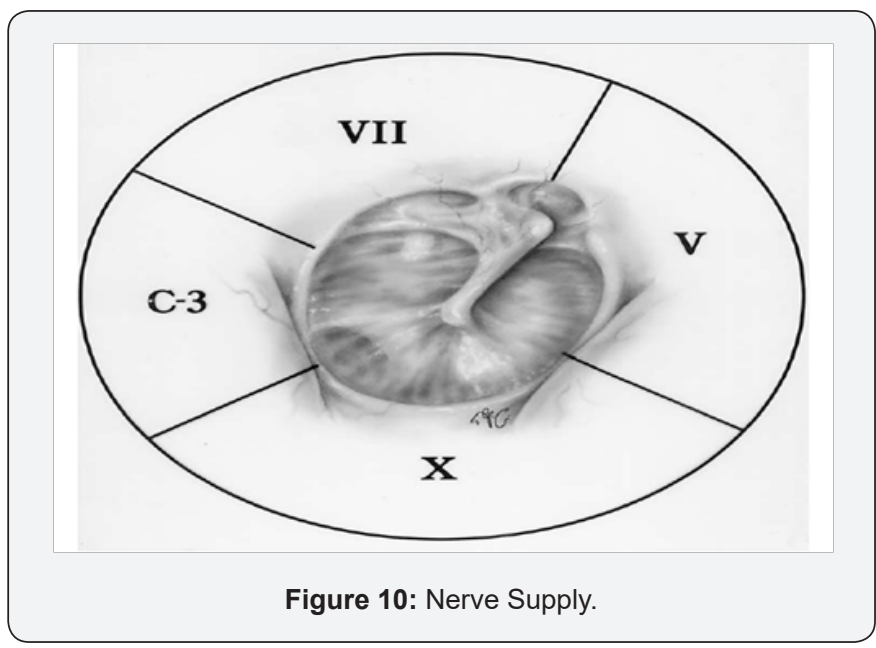

2. Middle Ear (Figure 11)

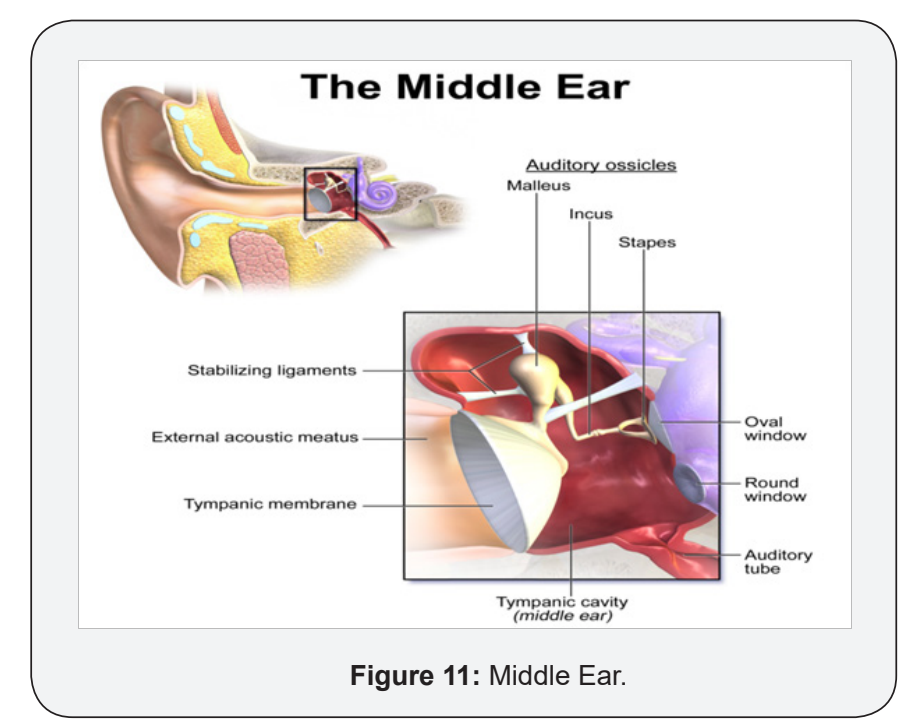

1. Ossicles

2. ME muscles

3. ET

4. ME cavities 


\section{Global Journal of Otolaryngology}

\section{Mastoid process}

\section{Relations (Figure 12).}

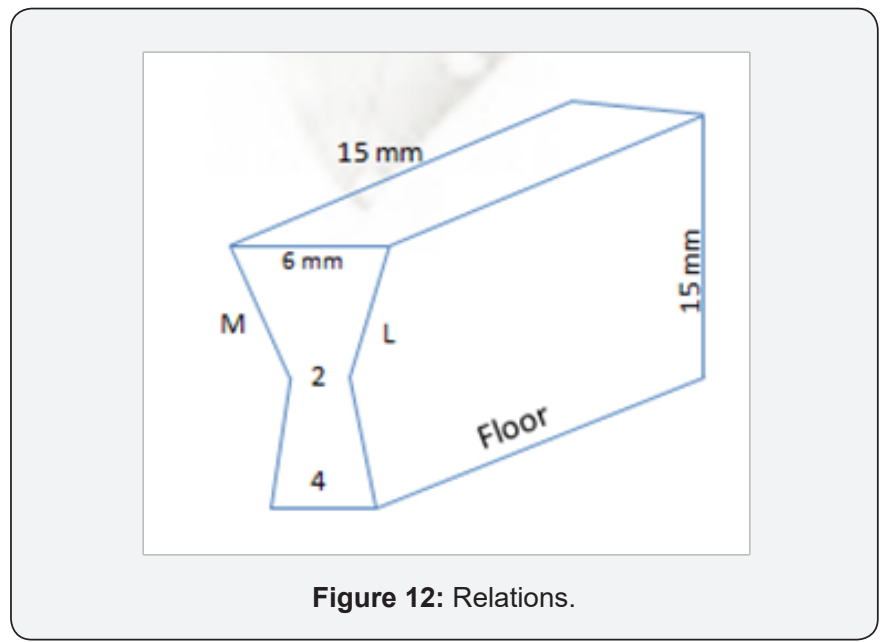

Lateral wall -> tympanic membrane, scutum (bony attic).

Floor: Jugular bulb

Anterior wall ->

1. opening of the eustachian tube,

2. Int. carotid a. canal present and

3. tensor tympani semicanal.

4. attachment of ant malleolar ligament canal for Chorda Tympani.

\section{Medial wall anteriorly:}

cochleariform process

4. Medially: Promontory of cochlea (Figure 13)

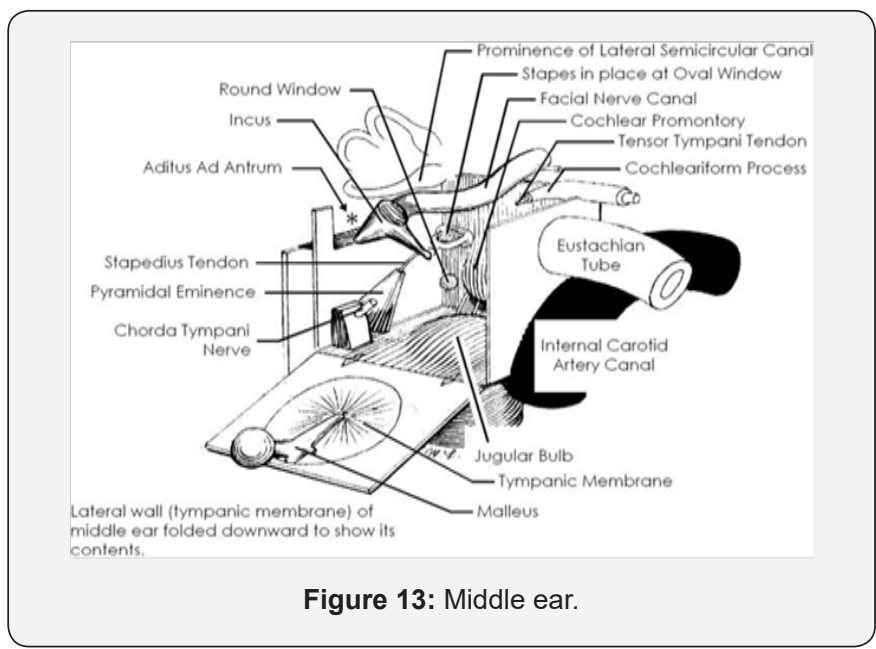

**Medial Wall:

1. Posterosuperior to the promontory: Oval window

2. Posteroinferior to it: Round window superior to the oval window -> The facial nerve canal prominence, above which LSCC.

3. The posterior wall separates the tympanic cavity from the mastoid (Figure 14).

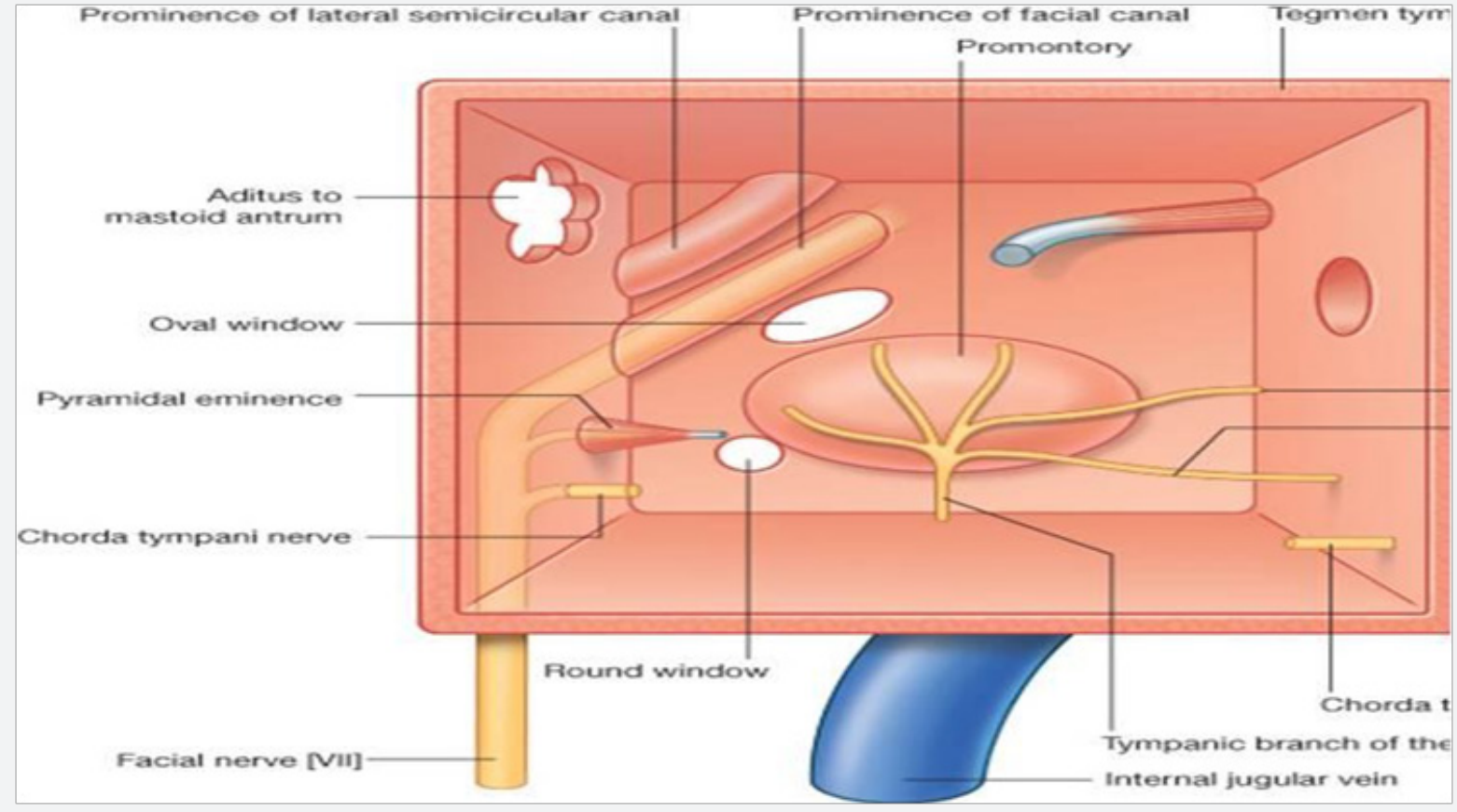

Figure 14: Medial wall. 


\section{Global Journal of Otolaryngology}

a) Roof $->$ Thin bony plate (tegmen tympani)

b) Posterior wall (superiorly) -> Aditus ad antrum

c) Posteriorly: 1-> Facial recess -> Lat. To pyramid medial: vertical part of 7 th $n$.
Lateral: Chorda Tympani and Tympanic annulus Superior: fossa incudes 2-> Sinus Tympani -> Medial to Pyramid Posteriorly -> Pyramid (stapedius muscle) -> fossa incudis -> accommodates the short process of the incus Chorda tympani nerve ->enter from opening between poserior and lateral walls (Figure 15)

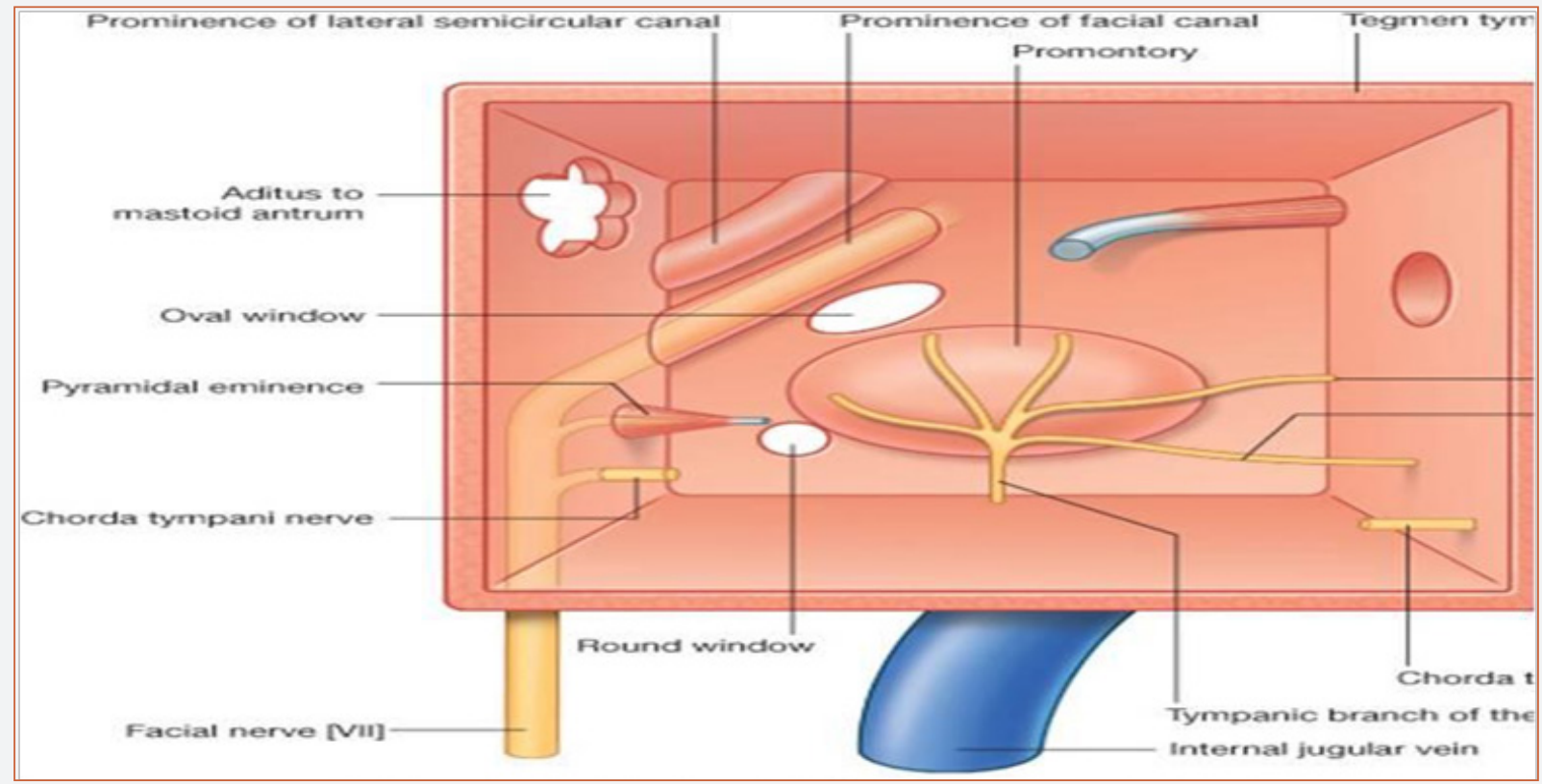

Figure 15: Thin bony plate

\section{Ossicles}

\section{a) Malleus}

8 to $9 \mathrm{~mm}$ long and weighs $25 \mathrm{mg}$.

Head -> articulate incus

Manubrium -> embedded between fibrous and mucous membrane layers of the eardrum.

Neck

Lateral process

Anterior process near the junction of the neck and manubrium (Figure 16).



b) Incus

$7 \mathrm{~mm}$ long and weighs $30 \mathrm{mg}$.

Short process -> is posteriorly oriented and is accommodated by the fossa incudis on the back wall of the middle ear.

Body

Long process -> descends to end at a rounded nodule called the lenticular process -> articulates with the head of the stapes (Figure 17).

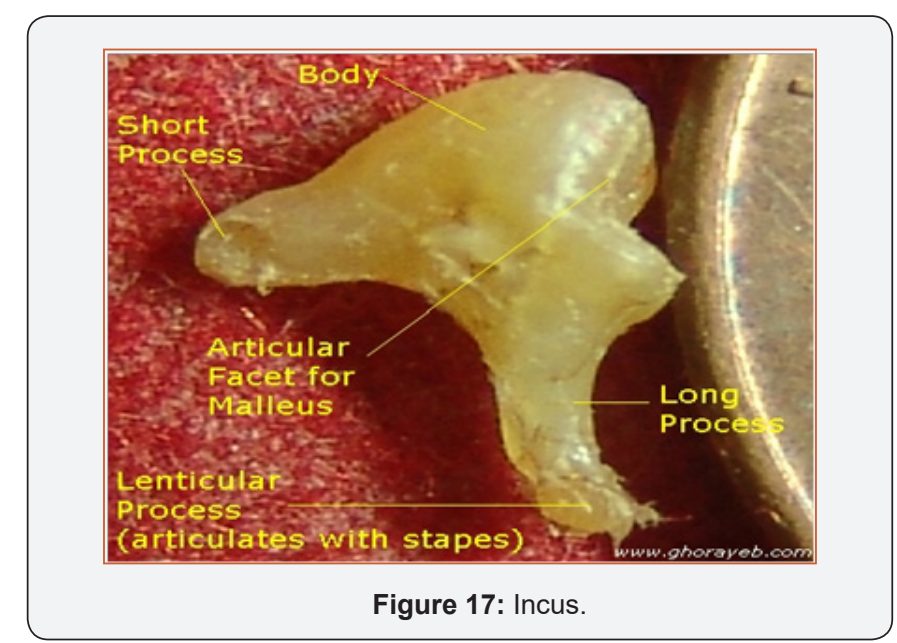




\section{c) Stapes}

$3.5 \mathrm{~mm}$ long, and the footplate surface area of $3.2 \mathrm{~mm}^{2}$ weighs 3 to $4 \mathrm{mg}$.

Head is connected via the neck to two crura $->$ anterior and posterior crura, which lead down to footplate.

Obturator foramen ->Central

attached to the oval window by the annular ligament (Figure 18)

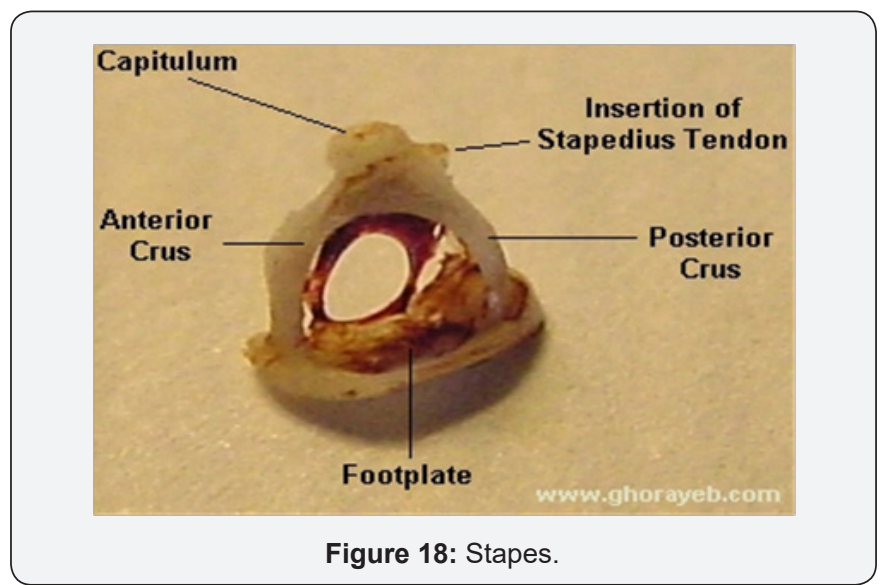

Ligaments attached to Ossicular chain and middle ear walls:

1. Superior malleal ligament $->$ from the roof of the attic down to the head of the malleus.

2. Anterior malleal ligament from the anterior tympanic wall to the anterior process of the malleus.

3. Lateral malleal ligament -> from the bony margin of the notch of Rivinus to the neck of the malleus.

4. Posterior incudal ligament (actually a fold of mucous membrane rather than a ligament) runs from the fossa incudis to the short process of the incus (Figure 19).

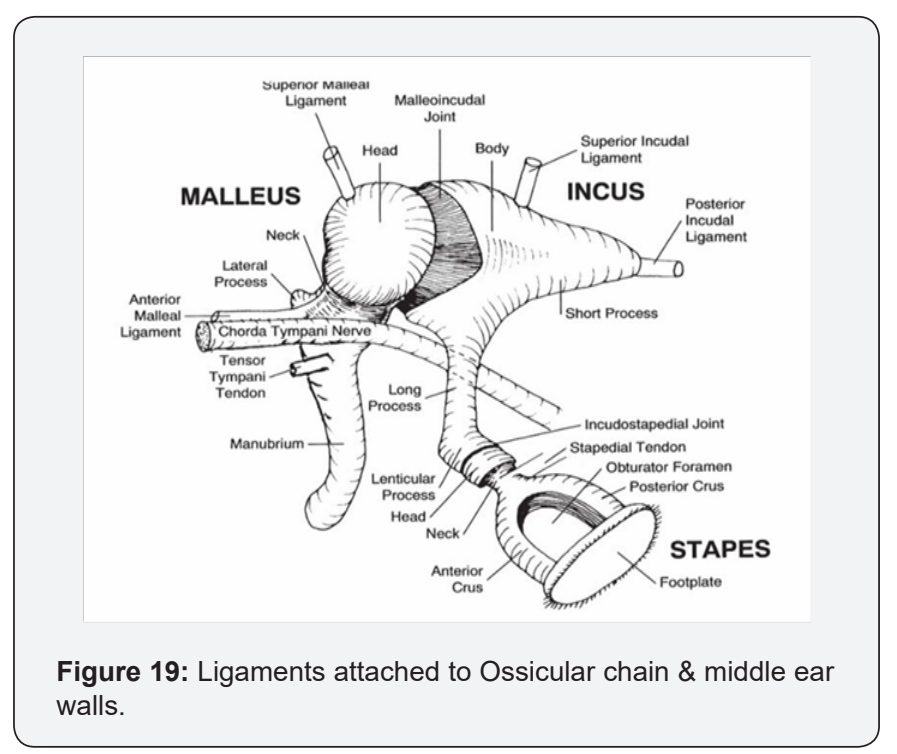

\section{Middle Ear Muscles}

\section{Tensor tympani muscle:}

It is housed within the tensor tympani semicanal superior to the Eustachian tube. $25 \mathrm{~cm}$ long

Origin: from the

I. cartilage of the ET,

II. walls of its semicanal

III. sphenoid bone adjacent to it

a) Tendon bends around cochleariform process and proceeds to insert on the malleus at the top of the manubrium near the neck.

b) Contraction of the tensor tympani -> stiffening the ossicular chain.

c) Innervated by the trigeminal nerve (Figure 20).

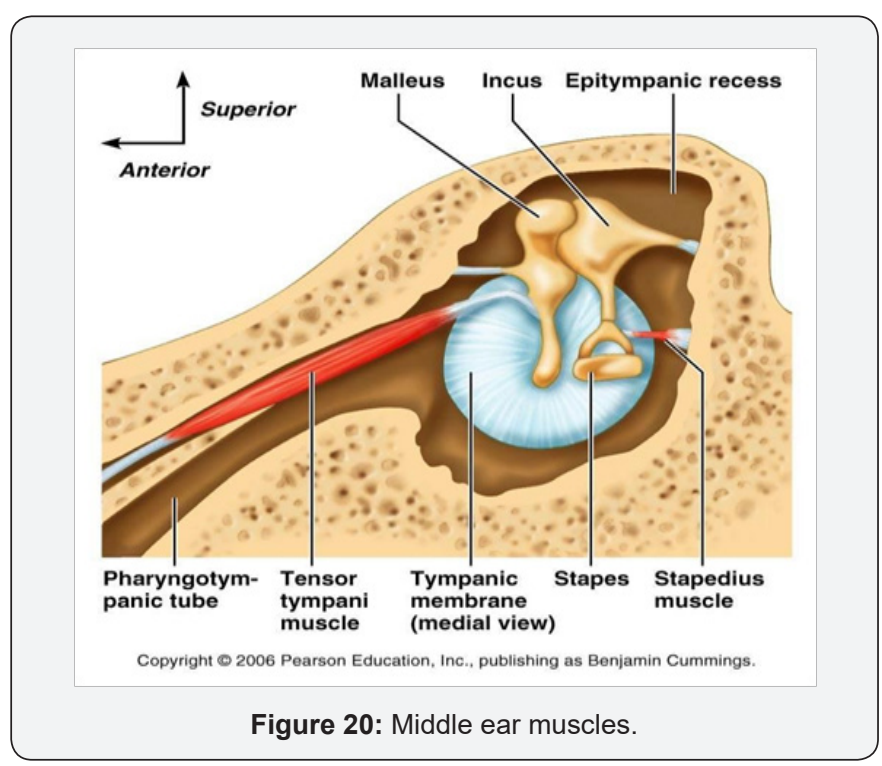

\section{A. Stapedius muscle}

i. The smallest skeletal muscle in the body length $->6.3 \mathrm{~mm}$.

ii. Innervation: the facial nerve.

The stapedius tendon from pyramidal eminence apex -> runs anteriorly to insert on the neck of the stapes posteriorly.

iii. Contraction of the stapedius ( $>80 \mathrm{~dB}$ ) pulls the stapes posteriorly $\rightarrow>$ stiffening the ossicular chain $->$ reduce the energy that is delivered to the inner ear.

iv. Gain control mechanism $\rightarrow$ keep cochlear input constant $->\uparrow$ dynamic range

v. $\downarrow$ self generated noise (chewing, vocalization) (Figure 21). 




B. Eustachian Tube

\section{A. Function:}

I. Aeration and drainage of the middle ear.

II. equalize air pressure to be the same on both sides of the eardrum.

i. From the anterior middle ear wall to the posterior wall of the nasopharynx

ii. Tilting downward at an angle of $45^{\circ}$.

Eustachian tube is almost horizontal in infants and young children.

a) The first third of the tube -> surrounded by bone (3$6 \mathrm{~mm}$ in diameter),

b) The remainder is surrounded by an incomplete ring of elastic cartilage. The meeting point -> called the isthmus (1-2 mm diameter). c) The cartilaginous part à forms a valve that protect middle ear from pressure fluctuations in the pharynx and decreases transmission of a person's voice to the middle-ear cavity.

d) It has cilia that propel mucus from the middle ear to the nasopharynx.

e) The slit shaped cartilaginous part of the Eustachian tube allows transport of material from the middle-ear cavity to the nasopharynx but not the other way (Figure 22).

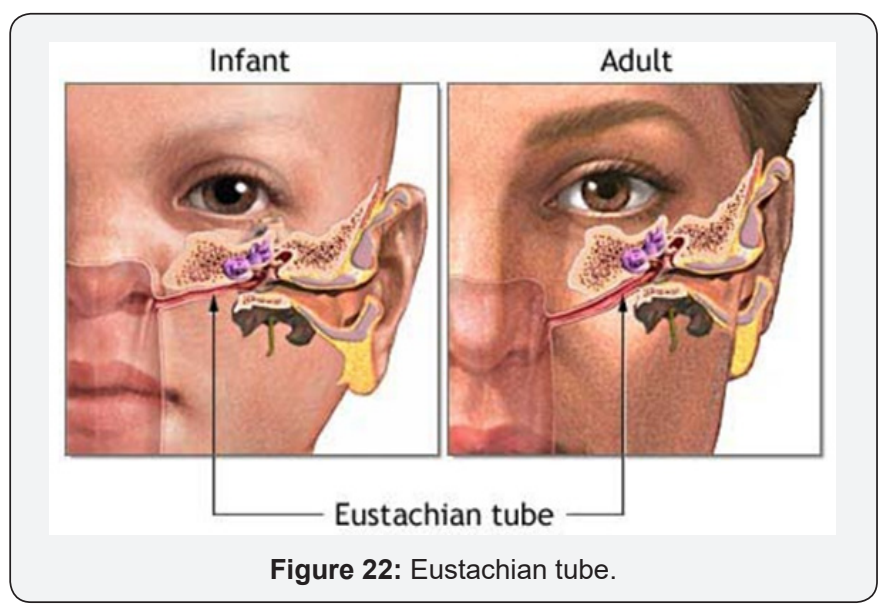

f) At rest, the cartilage keeps the Eustachian tube closed.

g) The lumen of the tube is opened by the pull exerted by the tensor palatini muscle. This occurs during swallowing, yawning...

h) Negative pressure develops in the middle ear $->$ when this mechanism fails to open the Eustachian tube frequently and effectively (Figure 23).

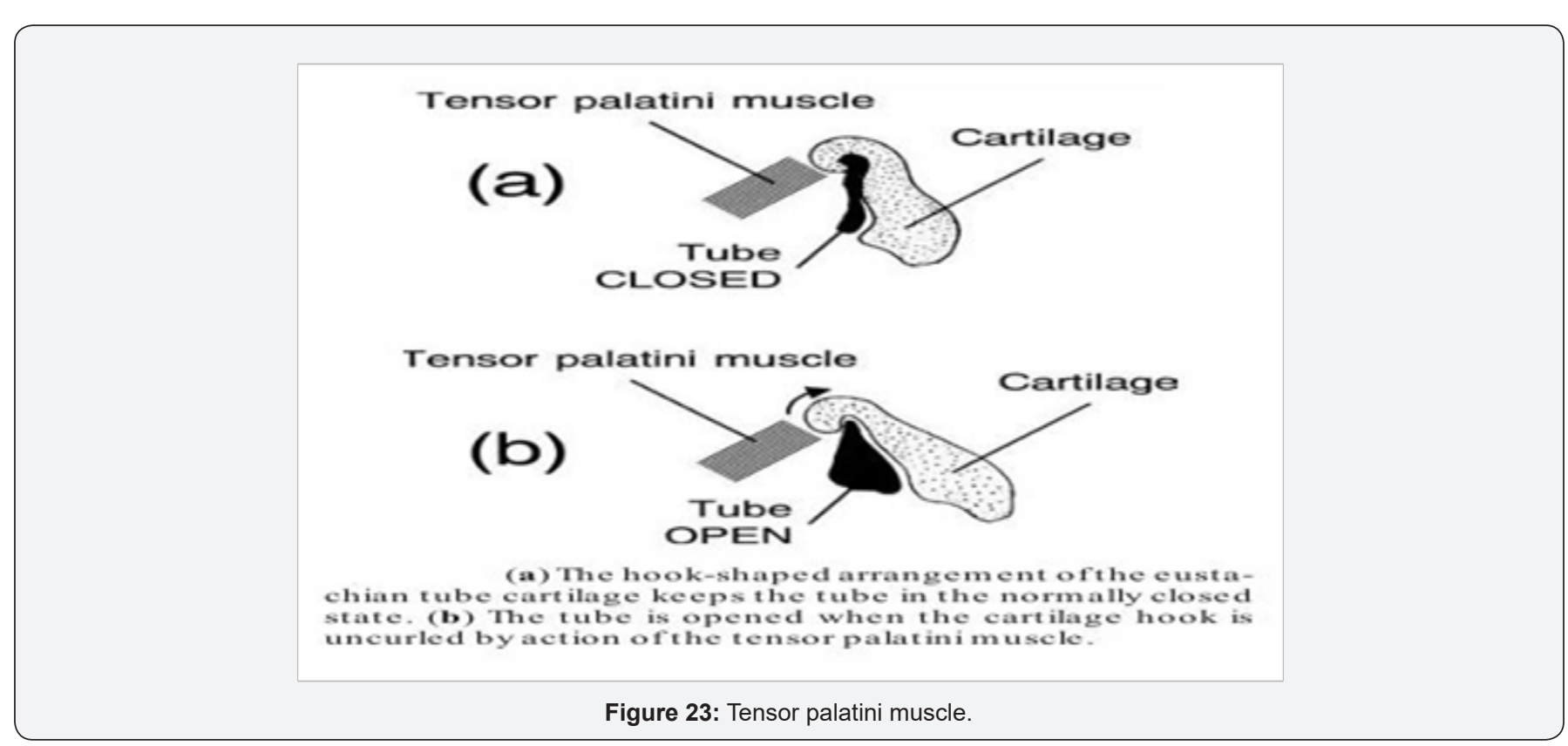


B.

1. Mesotympanum $\rightarrow$ between the tympanic membrane and the wall of the inner ear -> at level of parstensa. -> divided into 3 pouches (Inferior Incudal Space, Ant. and Post. Pouches of Von Troeltsch).

2. Epitympanum -> contain the head of the malleus and body of incus -> above level of pars tensa. ->include (Prussak's space and attic compartment (ant. and post. By sup malleolar fold).

Hypotympanum -> ET (area around it called protympanum) and lower part of middle ear cavity below tympanic membrane level.

- $\quad$ The total volume of the middle-ear cavities $->2 \mathrm{~cm}^{3}$

- If the volume of the mastoid air cells is included -> Total volume $10 \mathrm{~cm}^{3}$ (Figure 24).

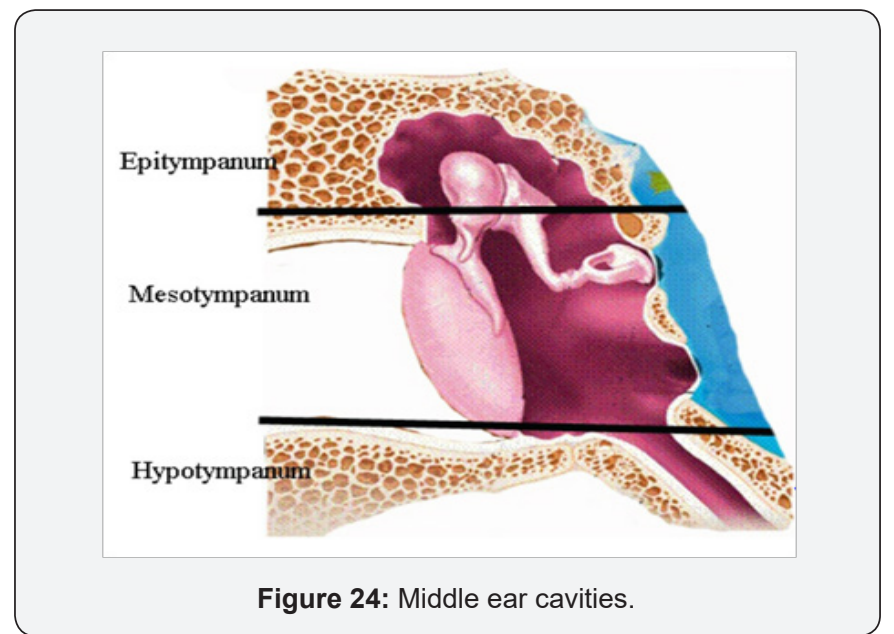

Mastoid Process (Figure 25)

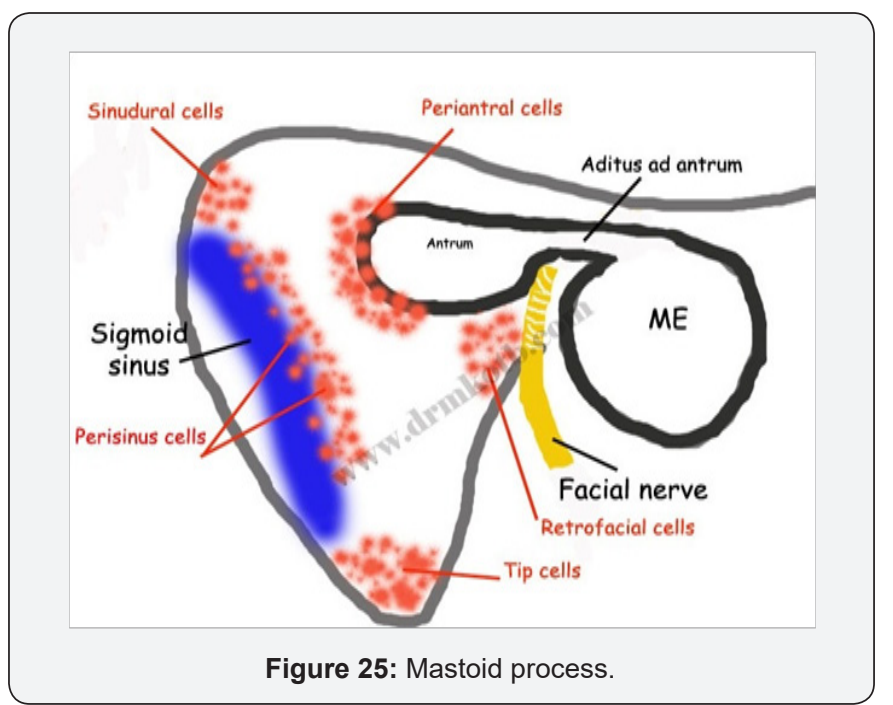

- Middle ear, antrum, and air cells compose a continuous, air-filled system->infection can spread from ME to the mastoid air cell system and beyond.
- $\quad$ Mastoid -> interconnecting air cells that vary widely in size, shape, and number. and according to cellularity:

*Well Pneumatized

*Diploetic

*Sclerotic

Classified According to their location into:
a) Zygomatic cells (in root of zygoma)
b) Tegmen cells
c) Perisinus cells
d) Perilabyrinthine cells
e) Peritubal cells
f) tip cells
g) Marginal cells
h) squamous cells.

First and largest air cell -> Tympanic antrum, which is located just behind the middle ear cavity ( $9 \times 14 \times 7 \mathrm{~mm})$.

i) Aditus ad antrum connects the antrum with the attic or upper part of the middle ear cavity. Related: *medially (bony prominence of HSCC) *laterally (Fossa Incudis) *Inferiorly (fallopian canal of Facial n.)

\section{j) Antrum:}

*The roof -> a thin bony plate -> tegmen tympani, which separates them from $->$ middle cranial fossa.

*Its medial wall separates it from: - lateral SCC. Endolymphatic Sac - Dura of posterior cranial Fossa

*Lat. Wall: $1.5 \mathrm{~cm}$ thick of squamous bone and Macewen's Triangle bounded by (linea Temporalis, posterosuperior margin of Ext. aud. Canal, Tangent of posterior margin of ext. aud. Canal)

*Anteriorly: from medial to lateral ( Facial n. canal,,, Aditus ad antrum and facial recess, deep bony EAC).

*Posteriorly: mastoid bone and air cells and Sigmoid Sinus

*Floor: Jugular bulb medial to facial canal - Digastric ridge origin of sternomastoid $\mathrm{m}$.

Mastoid develop from Squamous and petrous bone -> sometimes petrosquamous suture persists as bony plate called "Korner's Septum" separates superficial squamous cells from deep petrosal cells -> making surgery difficult

Mastoid develop from Squamous and petrous bone -> sometimes petrosquamous suture persists as bony plate called "Korner's Septum" separates superficial squamous cells from deep petrosal cells à making surgery difficult (Figure 26). 


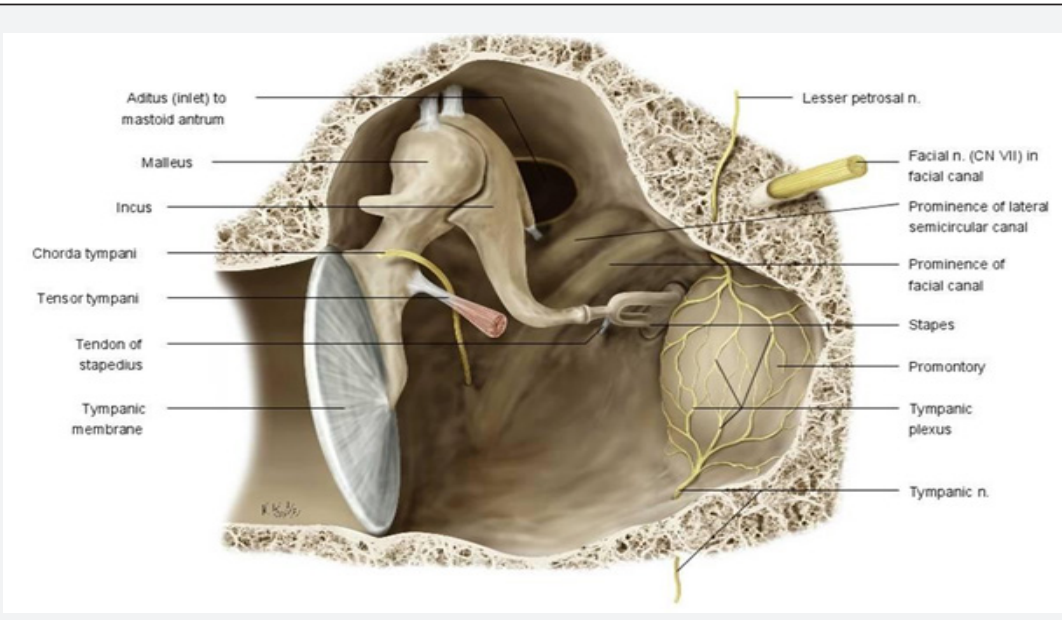

Figure 26: Mastoid develop from Squamous \& petrous bone.

\section{Blood supply of Tympanic cavity:}

From External Carotid and Internal Carotid:

i. Stylomastoid A.

ii. Inferior and Anterior Tympanic Arteries.

iii. Petrosal A.

iv. Caroticotympanic A. (from internal)

a) Venous Drainage Pterygoid plexus of veins which drain into superior petrosal sinus.

i. LYMPH NODES: Periauricular and retro pharyngeal nodes.

ii. NERVE SUPPLY Tympanic plexus located on the promontory of the medial wall.

iii. Tympanic branch of the glossopharyngeal (Jacobson nerve): This contributes to the

tympanic plexus and carry secretomotor fibers to parotid gland.

iv. Superior and inferior caroticotympanic nerves: These are branches from

sympathetic carotid plexus that join the tympanic branch of glossopharyngeal nerve

to contribute to the tympanic plexus.

v. Communication with a branch from the greater petrosal nerve

D. Eustachian tube

i. Blood Supply: Ascending pharyngeal and middle maningeal a.

ii. Venous drainage: -> pharyngeal and pterygoid venous plexus

iii. Lymph Drainage: retropharyngeal LN iv. Nerve supply: Pharyngeal branch of sphenopalatine ganglion, Nervous spinosus -> cartilageous portion - from tyympanic plexus -> bony part

\section{Inner Ear}

i. Bony Labyrinth

ii. Membranous Labyrinth (Figure 27).

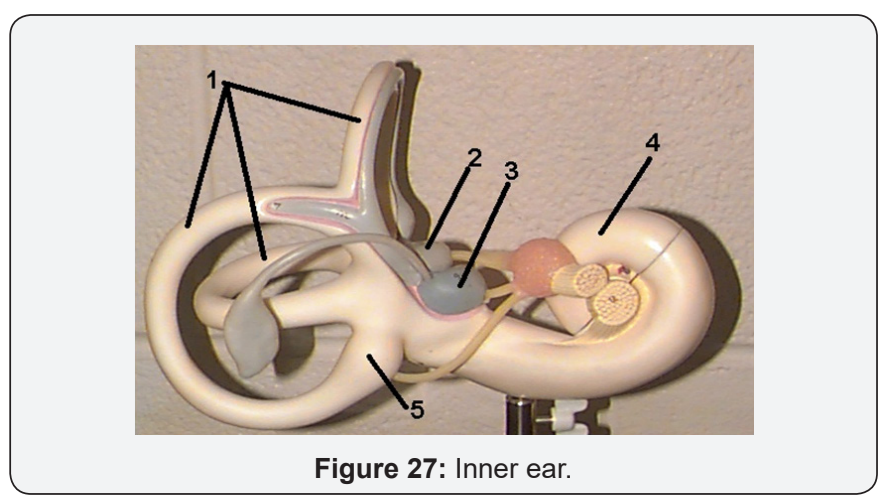

Bony Labyrinth

a) Cochlea : anterior part

i. $\quad 23 / 4$ turns around modiolus

ii. 3 compartments: SV, ST (Perilymph) and SM (endolymph)

iii. $\quad 30 \mathrm{~mm}$ long

b) Landmarks

i. Modiolus: central core with ${ }^{* *}$ base directed toward IAC, transmits VIII n. and vessels to cochlea, ${ }^{* *}$ Apex toward tensor typani $\mathrm{m}$.

ii. osseous spiral lamina: thin bony plate -> winds around modiolus like screw, ${ }^{* *}$ give attachment to basilar membrane, ** divides bony cochlea into 3 compartments.

iii. Rosenthal's canal: housing spiral ganglia 
iv. Scala vestibule: uppermost compartment, ${ }^{* *}$ closed by oval window and stapes footplate.

v. Scala tympani: lowermost, closed by round window (2ry Tympanic membrane)

vi. Promontary: basal coil of cochlea, ${ }^{* *}$ bulge in medial wall of middle ear.

vii. Helicotrema: communication between SV and ST at apex of cochlea

viii. Round window: on lateral wall of inner ear called "2ry TM"

\section{c) Vestibule}

I. Central portion

\section{Relations}

i. Anteriorly: communicates in front with the scala vestibuli of the cochlea and

ii. Posterosuperiorly: with the five openings of the semicircular canals.

iii. Laterally: oval window + footplate of stapes surrounded by annular ligament.

II. Medially:

i. Elliptical recess: lodge à utricle

ii. Spherical recess: lodge à saccule

iii. Both recesses separated by Vestibular crest -> which splits inferiorly to encloses Cochlear recess for cochlear n. fibers.

a) Three SCC à Posterior part, Sup, post, horizontal $2 / 3$ of a circle, $8 \mathrm{~mm}$ in diameter.

b) dilated end à Ampulla -> contain sensory end- organ

A. Superior SCC -> 15-20 mm long, transverse to axis of petrous bone, with ampulated anterolateral end.

B. Lateral SCC à $12-15 \mathrm{~mm}$ long, $30^{\circ}$ with horizontal, bulge into middle ear and aditus ad antrum, ampulated anterior end, posterior non-ampulated end open in lower part of vestibule below common crus.

C. Posterior SCC -> 18 - $22 \mathrm{~mm}$ long, parallel to posterior surface of petrous bone, ampulated lower end open on lower part of vestibule.

c) Common crus - $4 \mathrm{~mm}$, non-ampulated ends of superior and posterior SCCs join -> forming CC -> open in medial part of vestibule.

Vestibular aqueduct: narrow, bony canals arises from the medial wall of the vestibule and extends in an inverted ' $\mathrm{J}$ ' shape to the posterior surface of the petrous pyramid. It initially travels medially and parallel to the common crus (isthmus). a. Its apex at the isthmus and its base at the posterior fossa anterior to the sigmoid sinus.

b. A vestibular aqueduct is considered enlarged if it is greater than $1.5 \mathrm{~mm}$.

\section{Cochlear aqueduct:}

a. A small opening at the apex of a triangular depression in front of the jugular fossa,

b. in which a tubular prolongation of the dura mater ->

c. communicate between the perilymphatic space and the subarachnoid space, and

d. transmits a vein from the cochlea to join the internal jugular

It runs towards the cochlea in almost the same direction as the inner auditory canal, but situated more caudally (Figures 2831).
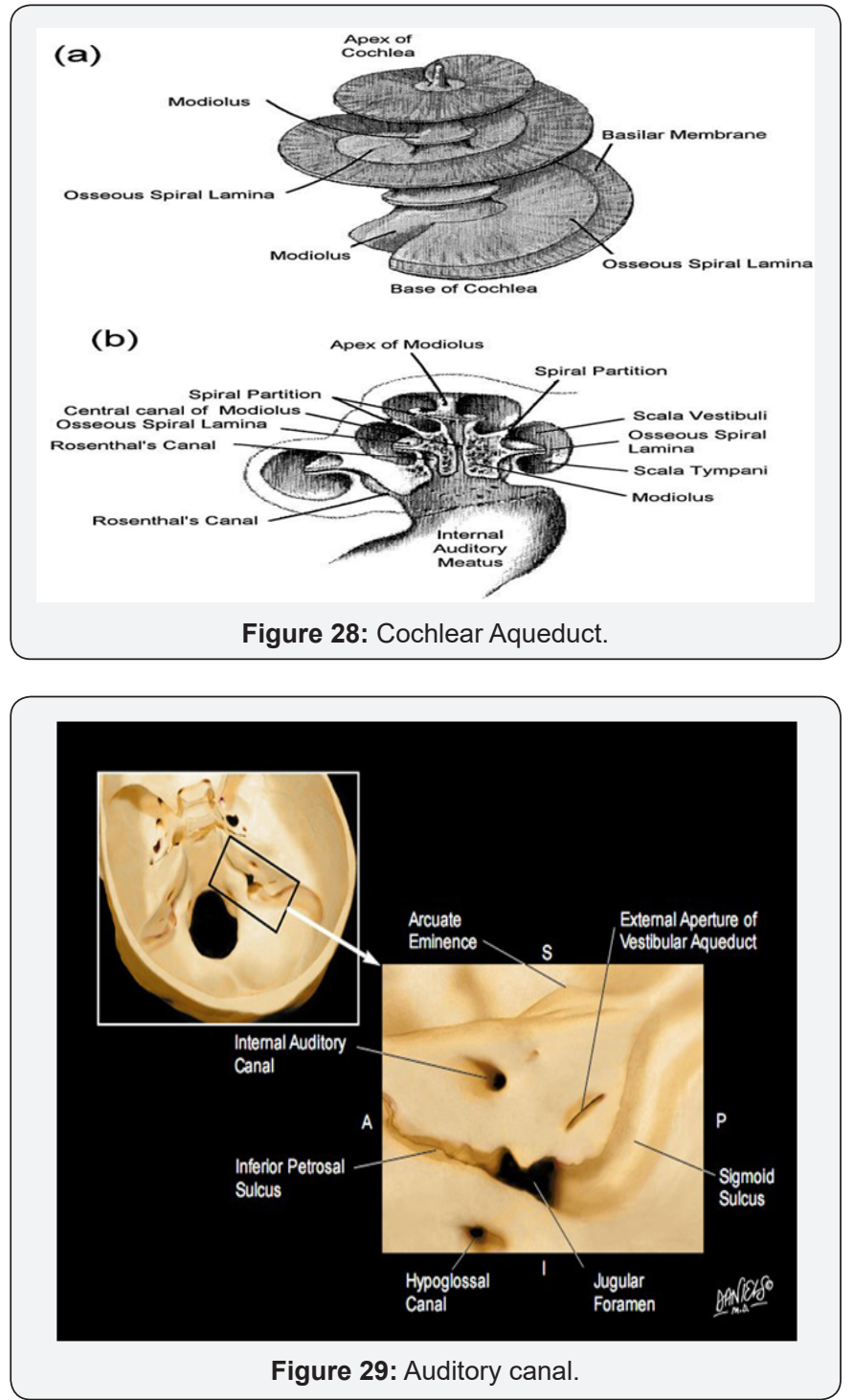


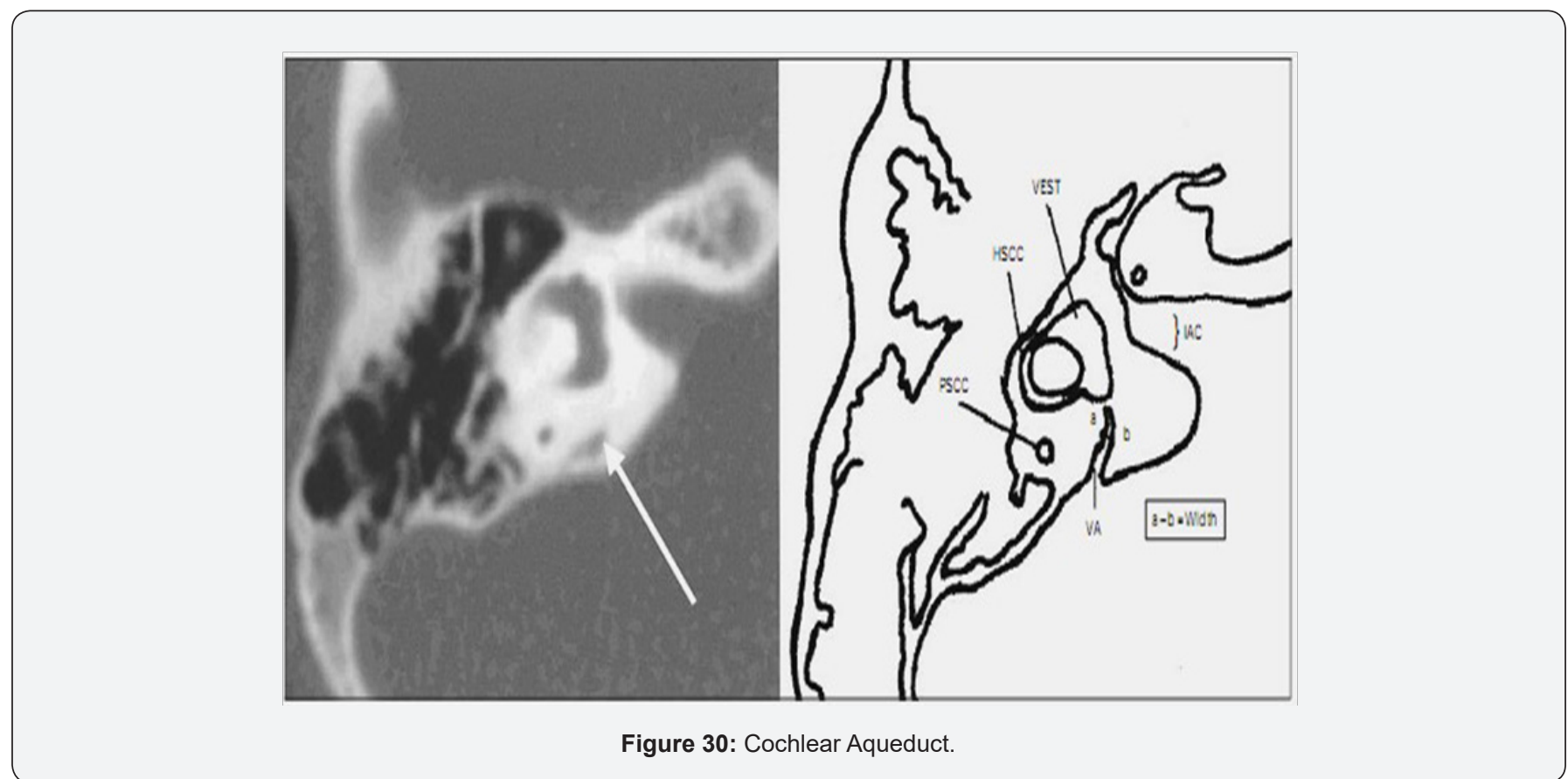



\section{Membranous Labyrinth}

Spiral duct of the cochlea: Scala media (endolymph).

i. $\quad 35 \mathrm{~mm}$ long

ii. Coiled into $23 / 4$ turns around modiolus

iii. Forming snail -> $9 \mathrm{~mm}$ width, $5 \mathrm{~mm}$ height

iv. Blind tube

v. Connected to saccule through ductus renuions

vi. Bounded by: Basilar membrane: *support organ of corti *narrow at base *wide at apex *has inner thin layer "zona arcuata" *outer thick layer "zona pectinata".

vii. Reissner's membrane: separates SV from SM

viii. Stria vascularis: contain vascular epithelium -> secrets endolymph.
ix. Organ of Corti: Sensory organ of hearing
x. Components:

xi. Tunnel of Corti: between IHC and OHC, contain fluid called corticolymph.

xii. Hair Cells:

A. IHC ........

B. $\mathrm{OHC} \ldots \ldots \ldots$

C. Supporting cells: Deiter's cells, between OHCs, Support OHCs

D. Cells of Hensen: outside Deiter's cells

E. Tectorial membrane: overlies organ of Corti, is a gelatinous matrix and delicate fibers

F. Shearing force between tectorial membrane and hair cells -> stimulate hair cells.

IHC:

a) Single row

b) About 3500

c) Flask shaped

d) Golgi apparatus, mitochondria, and other organelles associated with the extensive metabolic activity needed to support the sensory reception process (Figure 32).

OHC:

a) 3-4 rows

b) 12000

c) Tube like

d) contractile proteins able to shorten and lengthen in response to neural signals and chemical agents 


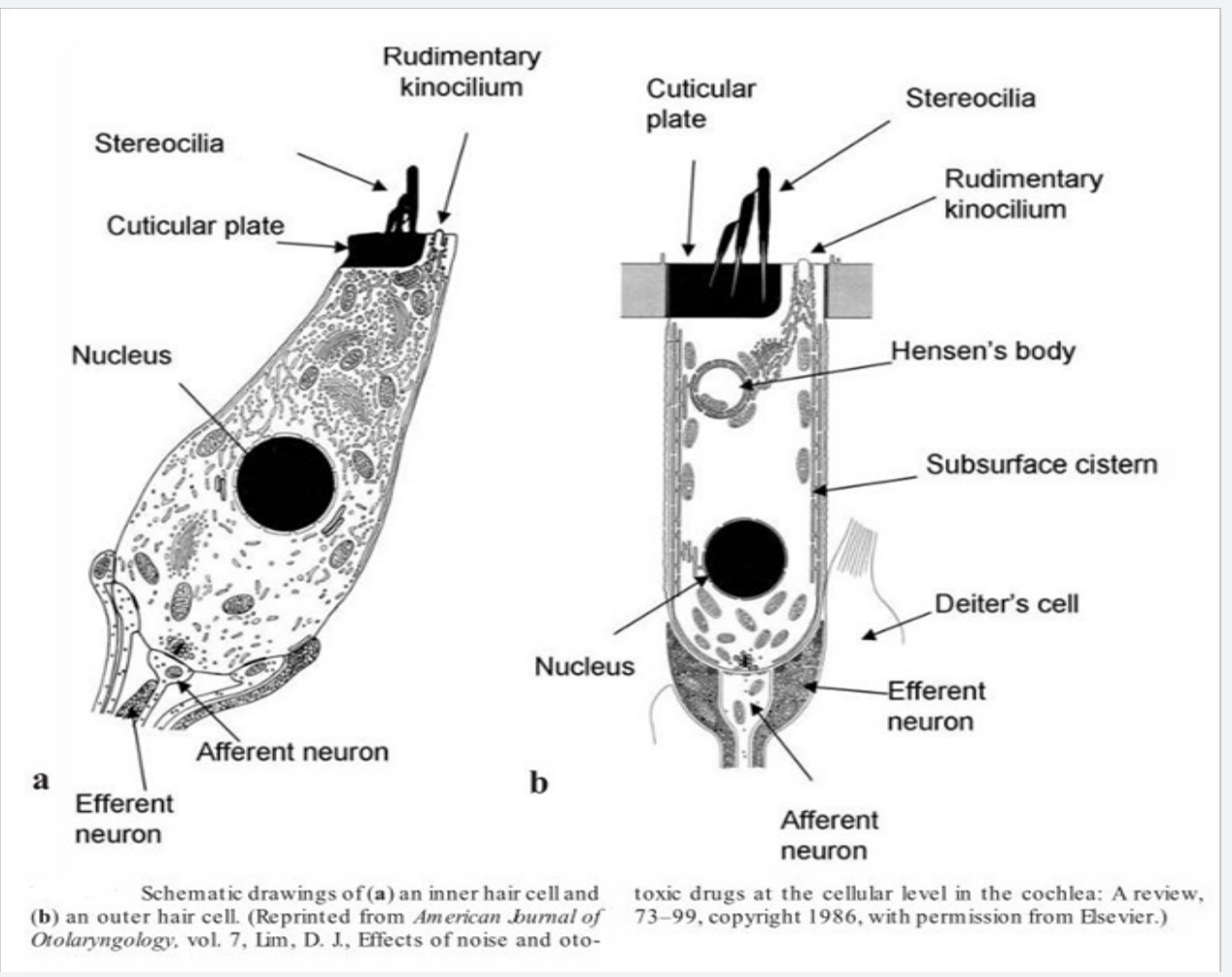

Figure 32: Hair cell has 50-100 stereo cilia and a single kinocilium.

I. Innervation of the Cochlea: involves both afferent and efferent neurons. The afferent nerve supply is made up of ascending sensory neurons that send signals from the cochlea to the nervous system. The efferent nerve supply includes a much smaller population of descending neurons that send signals from the nervous system to the cochlea. Approximately $95 \%$ of the afferent auditory neurons supply the IHCs, and the remaining $5 \%$ go to the OHCs. The distribution of efferent fibers is the opposite of that for the afferents; that is, most of them go to the OHCs (Figure 33).

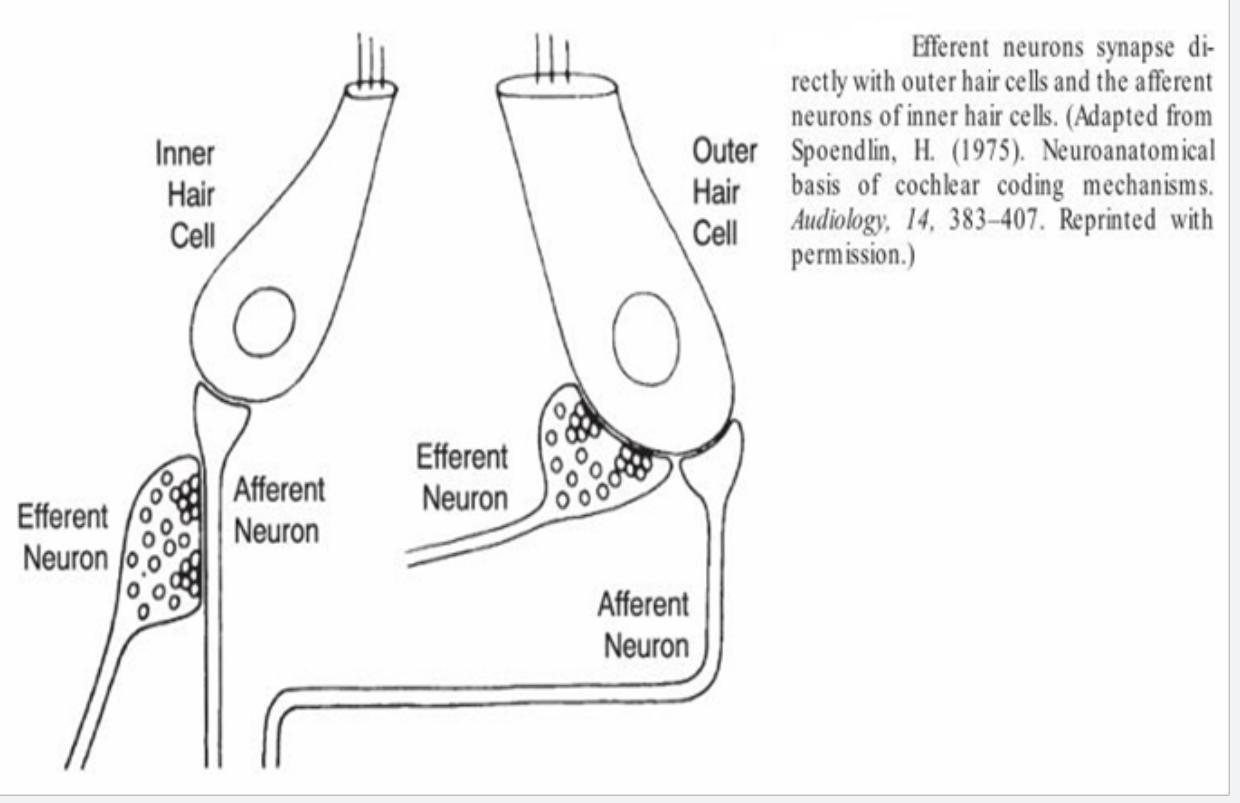

Figure 33: Efferent neuron. 


\section{Semicircular ducts:}

a) Respond to angular acceleration

b) At right angle to each other

c) superior and posterior ducts together have three open ends -> the crus commune and two ampullary ends.

d) The lateral semicircular duct has two open ends, thus,

e) There are five openings of communication with the utricle.

f) Ampulla: is a widening at canal joining with vestibule, contain a receptor organ called Crista.

g) Crista:

h) Base: vestibular hair cells and supporting cells

i) Sensory epithelial cells: *Type 1 and 2, *from upper surface of each project Kinocilium and multiple stereocilia *surrounded by supporting cells have microvilli on their upper surface. *Type 1 more in birds and mammals, like IHC (flask shaped) *Type 2 like OHC (tubular)

j) Top: is Cupulla -> Gelatinous mass formed by secretion from supporting cells, block flow of endolymph within the canal

k) In LSCC -> polarization when moved toward utricle

In Sup SCC and Post SCC -> polarized away from utricle

\section{Utricle:}

a) occupies the upper and the posterior part of the vestibule,

b) Oblong ( $\left.4.33 \mathrm{~mm}^{2}\right)$, with anterior slope $30^{\circ}$. Respond to linear acceleration (horizontal plane)

c) containing the sensory organ called the macula. Lies in floor of utricle, formed of 33000 hair cells, central curved line called "Striola".

d) Receive 5 openings of SCCs.

E. Saccule:

a) lies in the spherical recess of the vestibule $\left(2.4 \mathrm{~mm}^{2}\right)$.

b) near the opening of the scala vestibuli and the cochlea.

c) The saccule is continuous with the basal end of the cochlear duct via a very narrow short tube, the canalis reuniens.

d) Respond to linear acceleration (vertical plane).

e) Macula on its medial wall, contain only 18000 hair cells.

f) The sensory receptor organs of the utricle and saccule are called the maculae. g) Each macule contains vestibular hair cells that synapse with the eighth nerve.

h) Sensory neuroepithelium:

i) Type 1 and 2 cells

j) Type 1 more at area of striola

k) Kinocilium face striola in utricle and away from it in saccule

l) Curvilinear shape of striola $->3$ D orientation.

m) Otolithic membrane:

n) Consists of: *Gelatinous membrane *Subgelatinous space *Calcium carbonate crystals $\rightarrow$ small cylindrical hexagonal with pointed end called otoliths or otoconia, 3-19 um long.

o) Endolymphatic duct and sac

p) non sensory components of the endolymph filled, closed, membranous labyrinth.

q) The ED is a short single-lumen tubule,

r) only about $2 \mathrm{~mm}$ in length.

s) It is formed from the confluence of the utricular and saccular ducts.

t) ES à Part intraosseous, partly extraosseous in post. Cranial fossa between dura matter.

\section{u) Function:}

i. contribution in active ionic exchange of the endolymph with the CSF and

ii. reservoir of the endolymph in addition to a role in endolymphatic pressure regulation because their capability of absorbing water (Figures 34- 36)

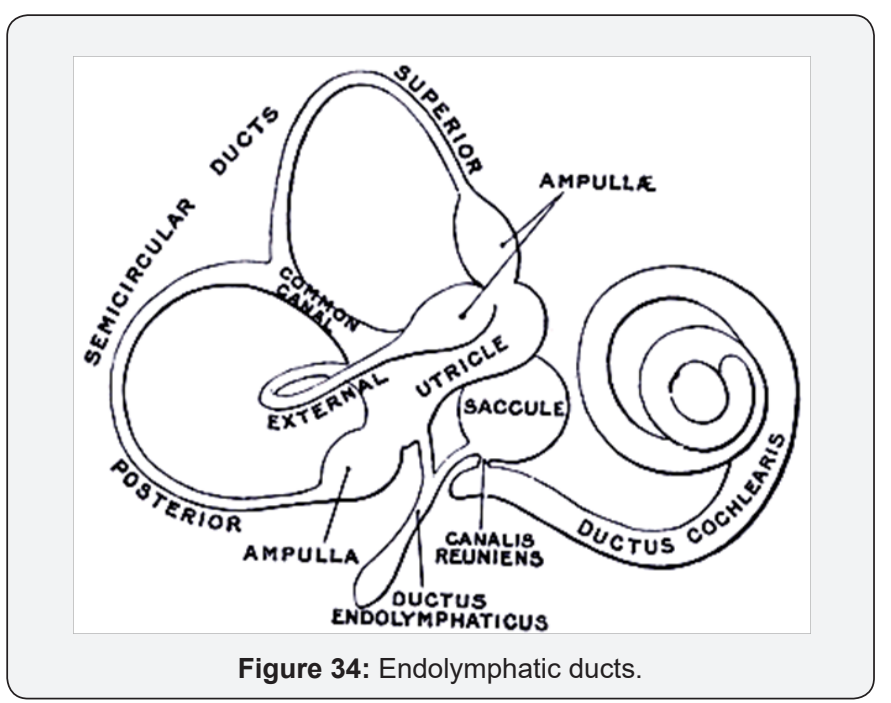




\section{Global Journal of Otolaryngology}

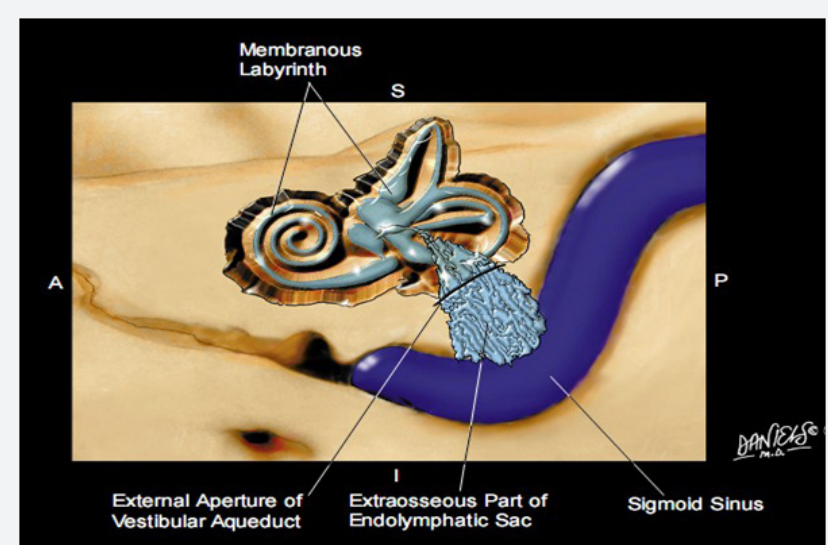

Figure 35: Membranous Labyrinth.



Figure 36: Different types of ducts. iii. Cochlear duct Figure 37:

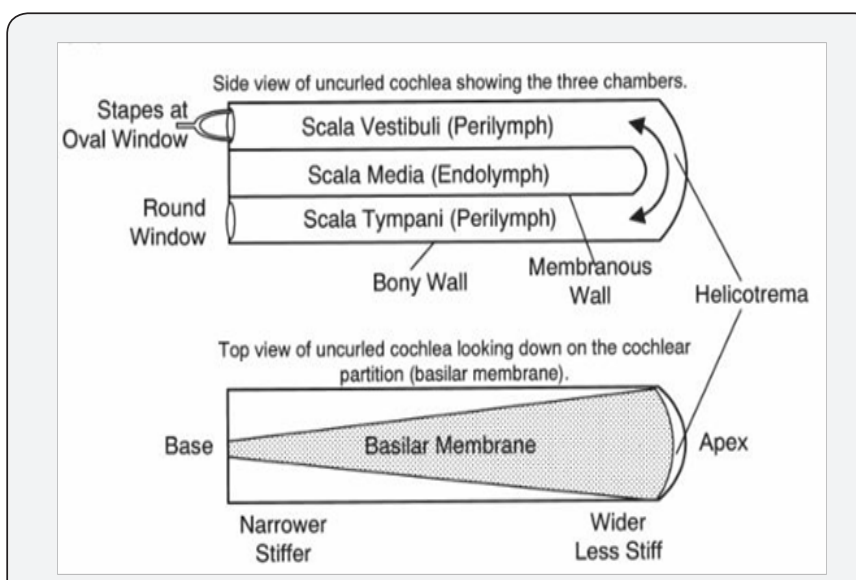

Figure 37: Side view of uncurled cochlea showing three chambers.
iv. Spiral ligament
v. The basilar membrane is a fibrous membrane
vi. Reissner's membrane

vii. The organ of Corti is the sensory organ for hearing and sits on the basilar membrane

viii. The tectorial membrane arises from the upper lip of the limbus and forms the overlying membrane of the organ of Corti. composed of collagen fibers

ix. Tunnel of Corti (Figures 38-43)

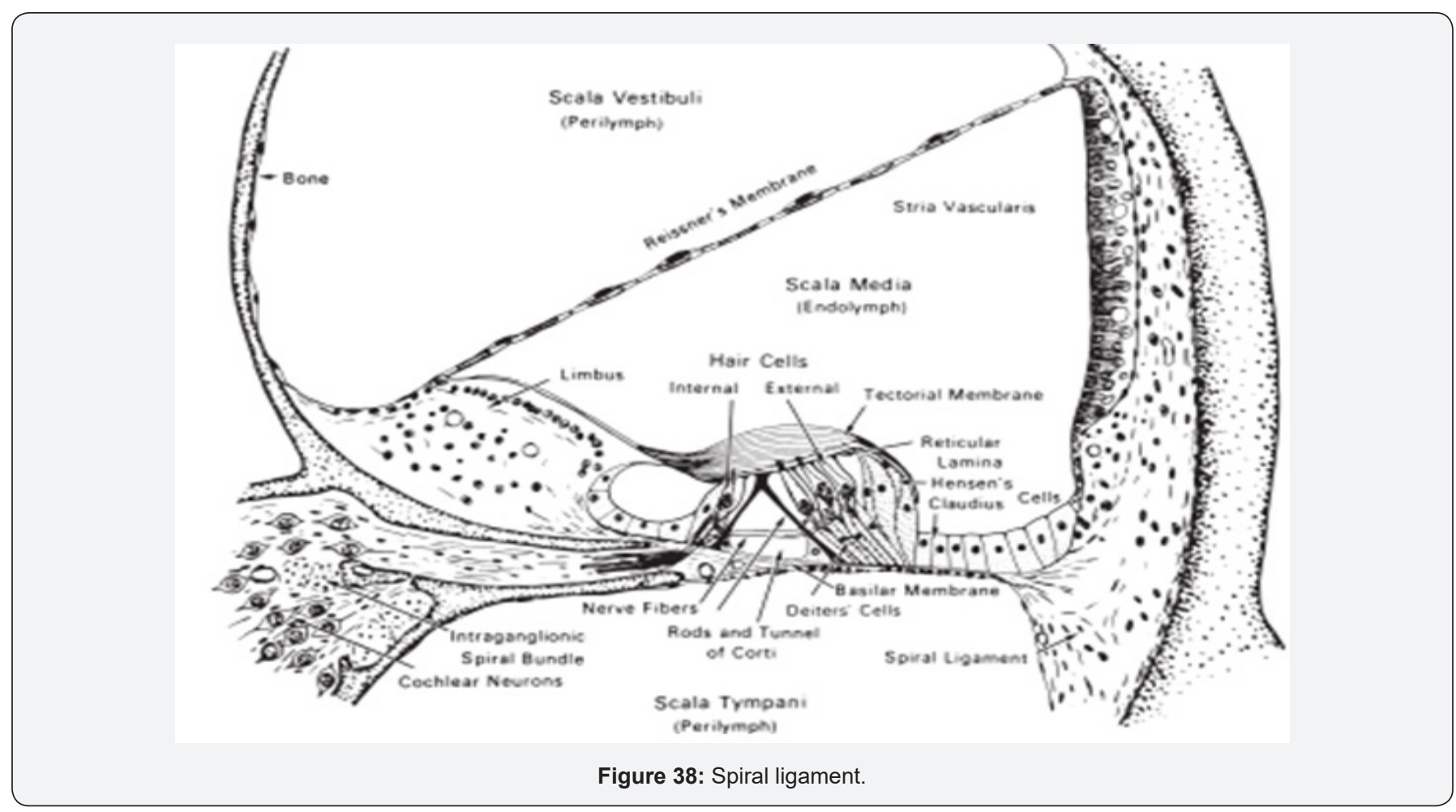




\section{Global Journal of Otolaryngology}
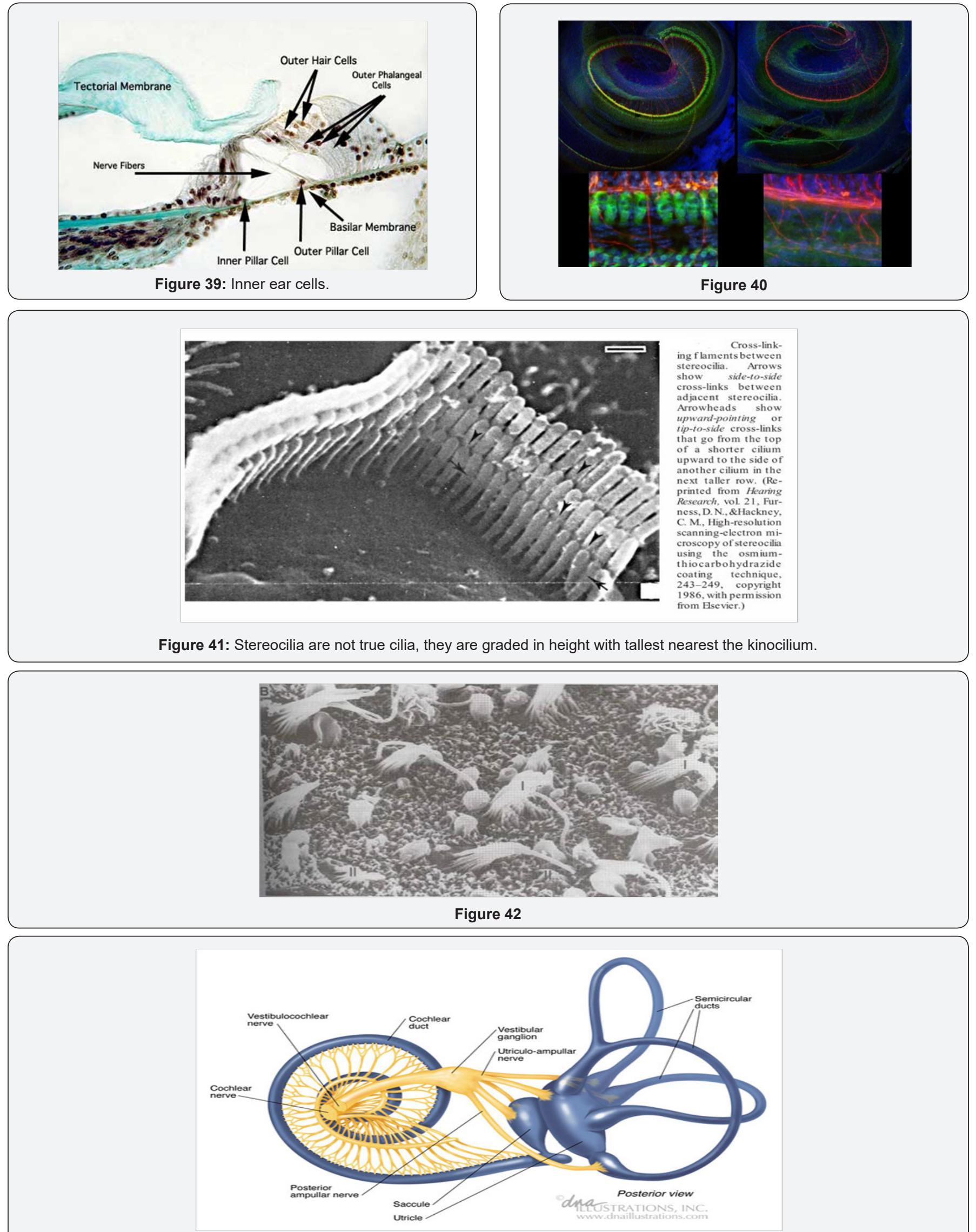

Figure 43: Posterior view. 


\section{Global Journal of Otolaryngology}

x. Vestibular Organs and Innervation

xi. Three SCC

a. Utricle and Saccule (Figure 44)

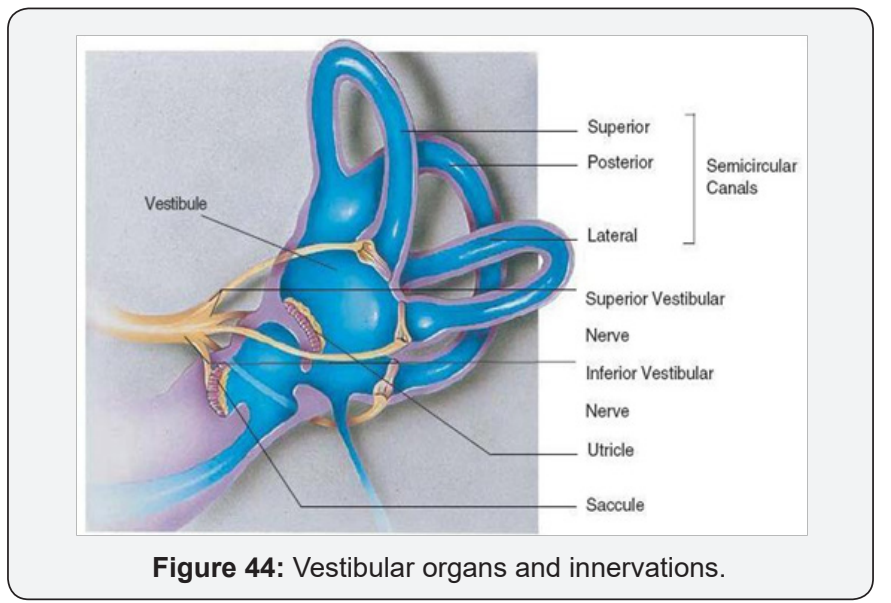

Figure 46: Inner view.

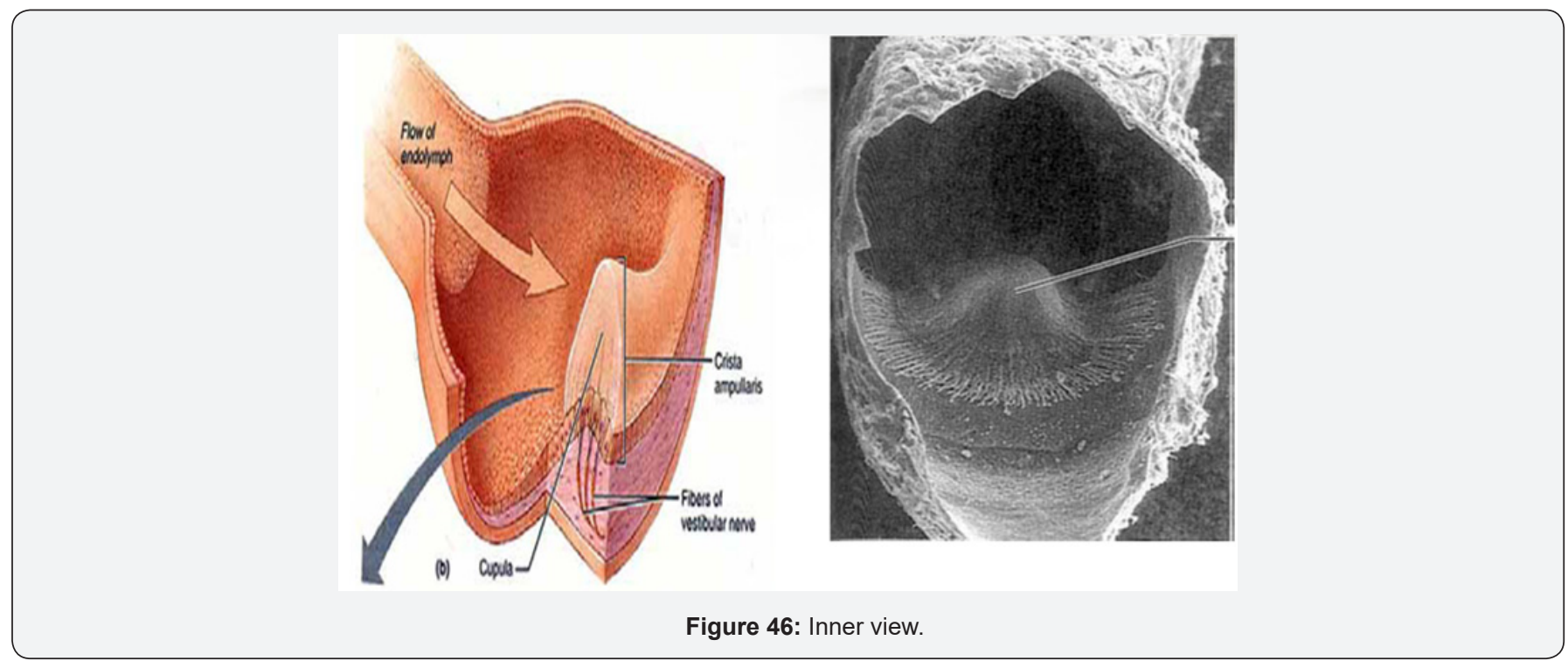

b. Semicircular canals (Figures 45 \& 46)



Figure 45: Semicircular canals.

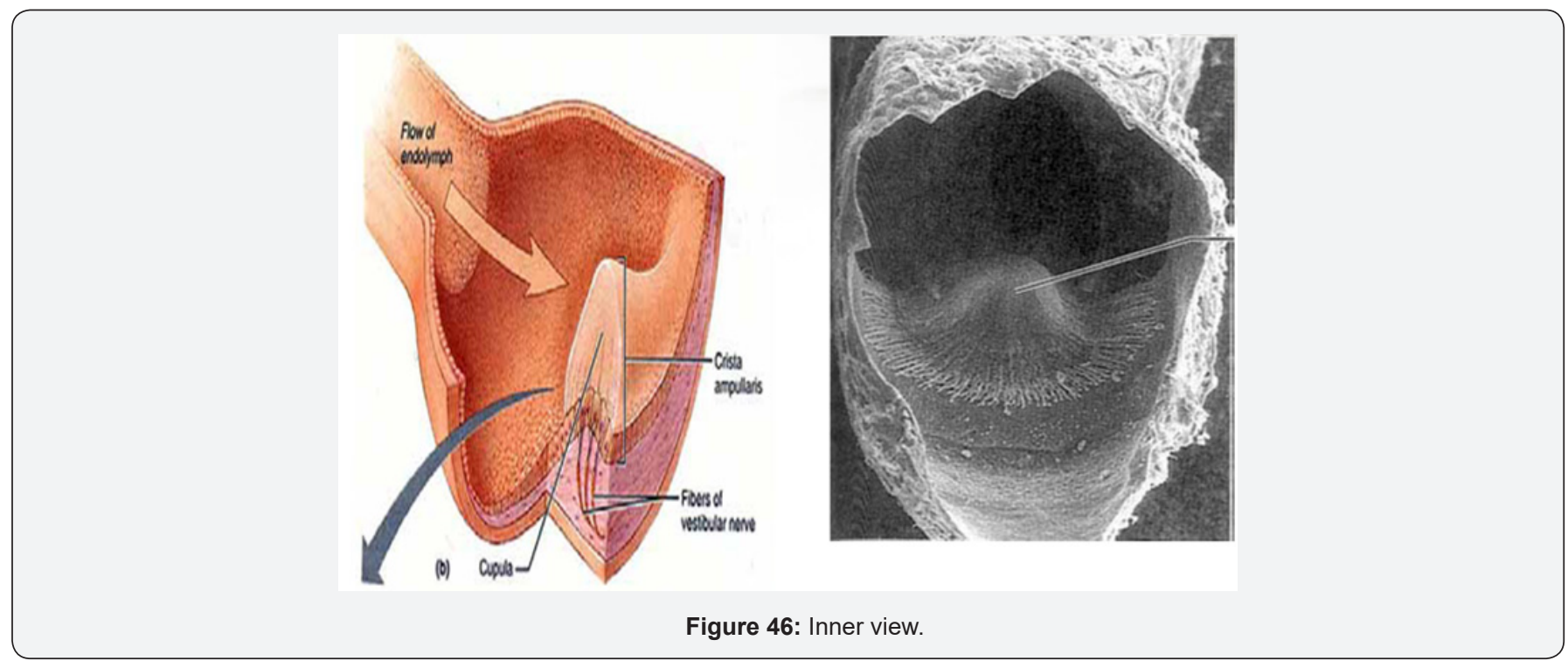

c. Utricle and Saccule (Figures 47 \& 48)
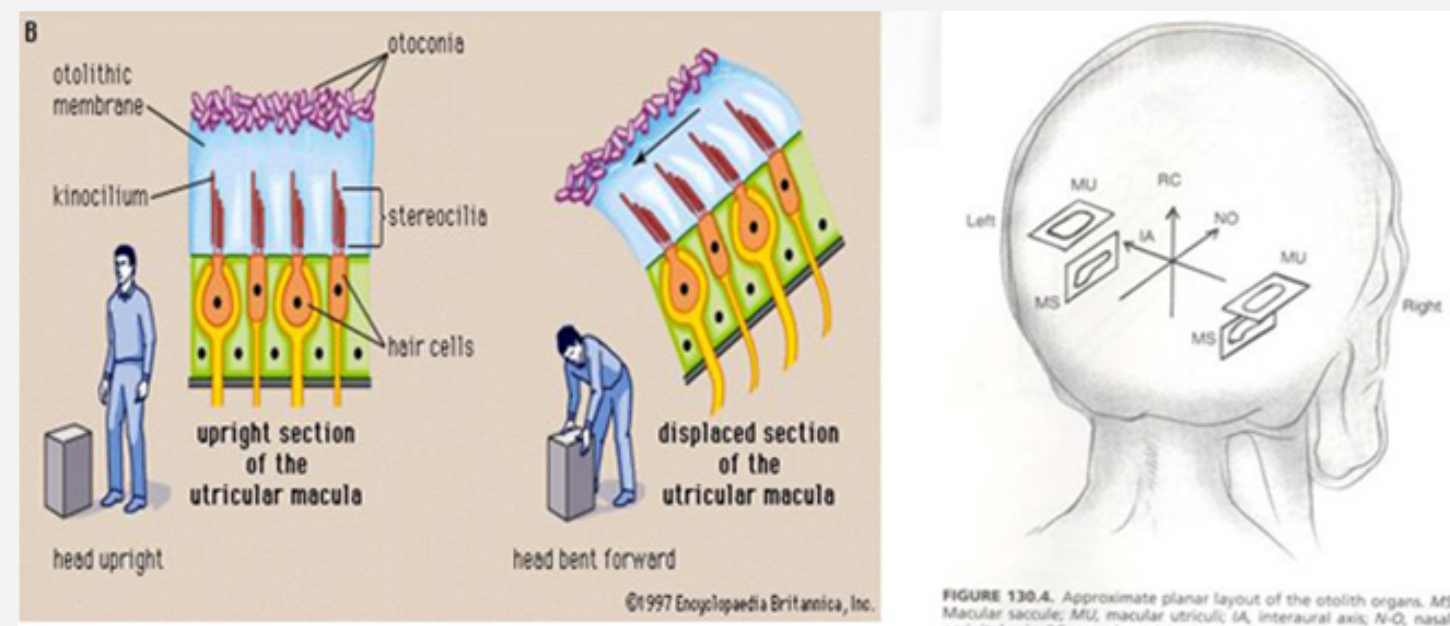

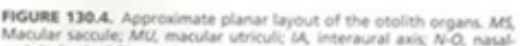



Figure 47: Utricle and Saccule. 


\section{Global Journal of Otolaryngology}

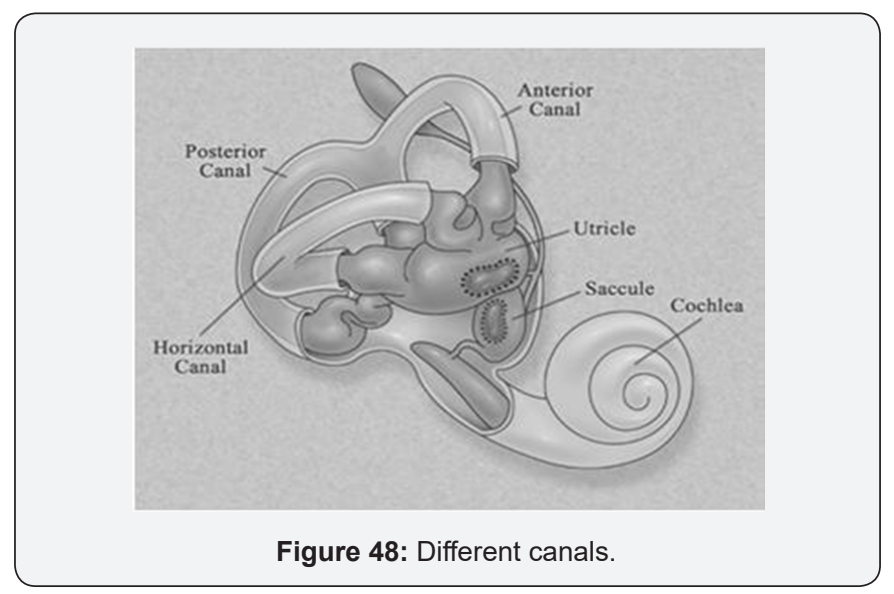

xii. Inner Ear Blood Supply

F. Labyrinthine artery (or IAA), the sole blood supply to the inner ear, either branches off from the AICA (most common) or from the basilar artery directly. -> anterior inferior cerebellar artery-> the internal auditory artery. Within the internal auditory canal, the internal auditory artery irrigates the ganglion cells, nerves, dura, and arachnoid membranes and divides into two main branches:

1. The common cochlear artery -> further branches into the - main cochlear artery -> supplies the apical $3 / 4$ of the cochlea - vestibulocochlear artery, -> the posterior vestibular artery $->$ to the inferior part of the saccule and the ampulla of the posterior semicircular canal and the -> cochlear ramus -> the cochlear ramus irrigates the basal one fourth of cochlea.

2. The anterior vestibular artery -> supplies the utricle, superior part of the saccule, and ampullae of the anterior and horizontal semicircular canals.

3. Venous drainage -> *Internal Auditory vein, *veins of cochlear aqueduct and vestibular aqueduct à into inferior petrosal and sigmoid sinus.

4. Innervations: -> The vestibulocochlear nerve (cranial

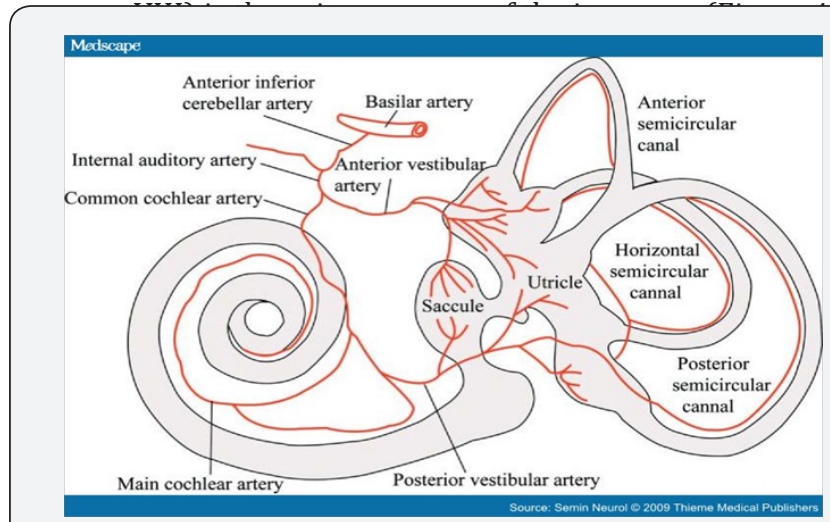

Figure 49: Inner ear blood supply.

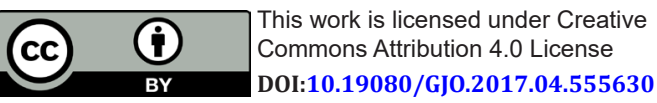

